$41(1) \mid 2012$

Varia

\title{
Las representaciones teatrales de «la muerte de Atahualpa»:¡una herencia de «moros y cristianos»?
}

Les représentations théâtrales de "la mort d'Atahualpa ": un héritage de "Maures et Chrétiens »?

The theatrical representations of «Atahualpa's death»: a legacy of «Moors and Christians»?

\section{Marine Bruinaud}

\section{OpenEdition}

\section{Journals}

Edición electrónica

URL: http://journals.openedition.org/bifea/1202

DOI: $10.4000 /$ bifea.1202

ISSN: 2076-5827

\section{Editor}

Institut Français d'Études Andines

\section{Edición impresa}

Fecha de publicación: 1 enero 2012

Paginación: 81-121

ISSN: 0303-7495

\section{Referencia electrónica}

Marine Bruinaud, «Las representaciones teatrales de «la muerte de Atahualpa»:¿una herencia de «moros y cristianos»? », Bulletin de l'Institut français d'études andines [En línea], 41 (1) | 2012, Publicado el 01 agosto 2012, consultado el 06 noviembre 2020. URL : http://journals.openedition.org/bifea/1202 ; DOI : https://doi.org/10.4000/bifea.1202

\section{(c) $(1) \odot$}

Les contenus du Bulletin de l'Institut français d'études andines sont mis à disposition selon les termes de la licence Creative Commons Attribution - Pas d'Utilisation Commerciale - Pas de Modification 4.0 International. 


\title{
Las representaciones teatrales de «la muerte de Atahualpa»: ¿una herencia de «moros y cristianos»?
}

\author{
Marine Bruinaud*
}

\section{Resumen}

Desde los años 1950, los estudios sobre las representaciones teatrales de «la muerte de Atahualpa» suelen presentar estas como una herencia del llamado teatro incaico. Después de evidenciar los mecanismos historiográficos que han contribuido a la generalización de dicha opinión, este artículo propone nuevas vías de investigación al poner de manifiesto la relación existente entre las piezas de «la muerte de Atahualpa» y las representaciones españolas de «moros y cristianos», mediante un análisis comparativo de ambas tradiciones. Se pone de relieve de esta manera la necesidad de revisar lo comúnmente admitido sobre este tema y de abrir el debate a nuevas teorías.

Palabras claves: teatro, Atahualpa, moros y cristianos, herencia cultural, Perú

Les représentations théâtrales de "la mort d'Atahualpa » : un héritage de «Maures et Chrétiens »?

\section{Résumé}

Depuis les années 1950, les travaux sur les représentations théâtrales de « la mort d'Atahualpa » tendent à présenter celles-ci comme un héritage du dit théâtre inca. Après un récapitulatif des mécanismes historiographiques qui ont contribué à la généralisation de cette opinion, cet article propose de nouvelles pistes de recherche qui mettent en évidence la relation existante entre les pièces de « la mort d'Atahualpa » et les représentations espagnoles de « Maures et Chrétiens », à travers une

* Estudiante del Institut National des Langues et Civilisations Orientales (INALCO), 2 rue de Lille, 75343, París, Cedex 07. E-mail: marinebruinaud@hotmail.com 
analyse comparée des deux traditions. L'article met ainsi en évidence la nécessité de réviser les théories communément admises et d'ouvrir le débat à de nouvelles hypothèses.

Mots clés : théâtre, Atahualpa, Maures et Chrétiens, héritage culturel, Pérou

\title{
The theatrical representations of «Atahualpa's death»: a legacy of «Moors and Christians»?
}

\begin{abstract}
Since the 1950's, studies of the theatrical representations of «Atahualpa's death» tend to depict these as being a legacy of the so-called Inca theatre. After briefly examining the historiographic mechanisms that led to this general opinion, this article offers new avenues of investigation, highlighting the existing relationship between the plays about «Atahualpa's death» and Spanish representations of «Moors and Christians» through the use of a comparative study of both traditions. This article underlines the need to revise such commonly accepted interpretations of these dramas and opens up the debate to allow new hypotheses.
\end{abstract}

Key words: Theatre, Atahualpa, Moors and Christians, cultural legacy, Peru

En varios pueblos del Perú y de Bolivia, se mantiene la costumbre de representar, durante las fiestas patronales anuales, la captura y ejecución del Inca Atahualpa a mano de los conquistadores españoles. Tales representaciones, bilingües quechuacastellano $-\mathrm{y}$ en algunos casos aimara-castellano-, pueden adquirir formas variadas, desde la mera batalla fingida básicamente gestual, hasta la verdadera obra de teatro con abundantes parlamentos, pasando por el baile. Un coro de pallas o ñustas1 suele, además, acompañar y comentar la acción con sus cantos, sea en quechua o en castellano. En la mayoría de los casos conocidos, los parlamentos de la representación así como los cantos de las pallas vienen consignados por escrito en «cuadernos» o «libretos de ensayo». De forma general, dichas representaciones han venido a designarse bajo el nombre genérico de «la muerte de Atahualpa»2, sin duda por influencia de la más famosa entre ellas, la Tragedia de la muerte de Atahualpa que publicó Jesús Lara en los años cincuenta (Lara, 1957).

Fue precisamente en los años cincuenta cuando empezaron a desarrollarse las investigaciones sobre estas piezas. De hecho, las publicaciones de aquellos años iban a determinar el rumbo que adoptarían dichas investigaciones hasta en la

1 Las pallas o ñustas eran princesas incas.

2 Sin embargo, cabe destacar que si bien algunas de esas representaciones muestran parentesco, esta tendencia no es generalizada. Tal como lo precisa César Itier en un reciente artículo, las «muertes de Atahualpa» «forman un conjunto de piezas distintas que no se derivan de un prototipo común» (Itier, 2009: 215). Por eso hablaremos, en adelante, de las «muertes de Atahualpa» en plural. 
actualidad. Hasta entonces, si bien algunos estudiosos habían evocado la existencia de representaciones donde se dramatizaba la muerte del Inca, no se conocía ningún texto que permitiera su estudio detenido3. Los primeros fragmentos de alguna pieza de «la muerte de Atahualpa» aparecieron en 1945, en la novela folklorista Valle de Mario Unzueta. El autor describe en esta una fiesta en honor al Señor de Kanata, santo patrón del pueblo de Toco (Cochabamba, Bolivia), durante la cual presenció la representación cuyos parlamentos transcribe parcialmente.

Sin embargo, habrá que esperar a 1955 para que se dé a conocer un texto completo con la publicación de La conquista de los españoles de Clemente Hernando Balmori (1955). Se trata de la reproducción de un libreto de ensayo bilingüe quechua-castellano recogido en Oruro (Bolivia) en 1942. Tras una significativa introducción centrada en el tema del teatro prehispánico en México y en el Perú, C. Balmori afirma el origen prehispánico de este drama, así como la identidad indígena de su autor. Poco después, en 1957, Jesús Lara publica un nuevo texto bajo el título Tragedia de la muerte de Atahualpa, que descubrió, según dice, en Cochabamba en 1955, y cuyo origen sería igualmente prehispánico. El texto de Lara, sacado de un manuscrito fechado en Chayanta en 1871, tiene la particularidad de estar redactado exclusivamente en quechua. Se supone que allí los personajes españoles no se expresan más que moviendo los labios sin emitir ningún sonido. Después de proponer su análisis del texto, Lara afirma que habría sido compuesto «en los primeros años de la conquista por algún amauta [sabio inca] que hubo sobrevivido a la catástrofe» (Lara, 1957: 59), y que sería la versión prototípica al origen de las múltiples representaciones de «la muerte de Atahualpa» conocidas en la actualidad. La importancia del hallazgo brindó al texto de Lara una larga difusión, y este fue tomado, desde entonces, como documento de referencia para el estudio de las representaciones de «la muerte de Atahualpa». Sin embargo, César Itier ha demostrado, hace algunos años, que la supuesta Tragedia de Chayanta era una falsificación creada por el mismo Jesús Lara (Itier, 2001)4.

No se pondrá entonces en duda la necesidad de revisar todo cuanto se ha dicho y escrito sobre las «muertes de Atahualpa», tomando en cuenta que la mayoría de los estudios sobre el tema se basan en aseveraciones de Lara, directa o

3 El interés de los investigadores por el tema fue despertado por algunas referencias encontradas en la documentación colonial. Solo se precisará al respecto que la referencia más antigua a una «muerte de Atahualpa» que haya llegado hasta nosotros se debe al ingeniero francés Amédée Frézier, quien viajó a Chile y al Perú de 1712 a 1714. En el relato de su viaje, Frézier menciona que en varias ciudades del Perú se suele escenificar la muerte del Inca para la Natividad de la Virgen (Frezier, 1716: 250). El historiador potosino Bartolomé Arzáns de Orsúa afirma por su parte que se representó «la ruina del imperio inga» en 1555 en Potosí (Arzáns, 1965: I, 98). Sin embargo, se puede dudar de la veracidad de esta información. Según sus editores, Arzáns habría podido presenciar dicha representación a finales del siglo XVII y trasponerla al XVI por razones poco científicas. Véase al respecto el estudio de Lewis Hanke y Gunnar Mendoza en Arzáns, 1965.

4 Además del artículo de 2001, véase el más reciente artículo de 2009, donde C. Itier estudia en detalle el contexto que llevó a J. Lara a proceder a esta falsificación (Itier, 2009). 
indirectamente 5 . Es preciso pues volver a empezar desde cero, volver a plantear la cuestión del origen de las «muertes de Atahualpa» tomando en cuenta las numerosas piezas que, desde los años 1950, se han dado a conocer sin que se les preste la debida atención6.

\section{NUEVAS PERSPECTIVAS}

Aun antes de que fuera descubierta - $-y$ demostrada - la «superchería» de J. Lara, algunos estudiosos ya habían abierto el debate al proponer nuevas vías de investigación, conforme iban apareciendo nuevos textos de «la muerte de Atahualpa». Así Antonio Cornejo Polar, al confrontar las piezas publicadas por Balmori y Lara con las que presentaron, respectivamente, Francisco Iriarte y Wilfredo Kapsoli años más tarde, concluyó que las «muertes de Atahualpa» existían de manera escrita desde su origen, y expresó así su confusión:

«No está nada claro, sin embargo, si los textos que han llegado hasta nosotros tienen en efecto este origen [arcaico como proponen Lara y Arzáns], y si a través de él se asocian o no a las representaciones prehispánicas de las que hablan Garcilaso y otros cronistas; si se vinculan a las estrategias de la catequización y a una de sus formas preferidas, los autos sacramentales; o si de alguna manera reformulan, con materia andina, el esquema opositivo de las comparsas de moros y cristianos» (Cornejo Polar, 1990: 173).

La cuestión de una posible relación entre las «muertes de Atahualpa» y los «moros y cristianos», aquí evocada por A. Cornejo Polar, interesó de la misma manera a Berta Ares Queija, quien desarrolló el tema en un artículo de 1992. Pone de relieve el hecho de que, tanto en México como en Guatemala, se admite perfectamente la vinculación de las Ilamadas «danzas de la conquista» con los simulacros de combate introducidos por los españoles, mientras que en el caso del Perú la influencia de los trabajos de J. Lara impidió que se prestara atención al tema.

Por su parte, Pierre Duviols planteó la cuestión en dos artículos sucesivos, en 1999 y en 2000. En el primero, donde se centra en el análisis de la versión de Manás (Cajatambo) publicada por F. Iriarte, identifica los Comentarios Reales de Garcilaso de la Vega como fuente principal del drama, además de poner de relieve analogías

5 El trabajo de J. Lara inspiró a muchos estudiosos posteriores, tales como Nathan Wachtel, quien se refiere principalmente a Tragedia en La vision des vaincus (1971), estudio que adquirió una muy amplia difusión y fue tomado a su vez como referencia sobre el tema de las «danzas de la conquista», incluyendo las «muertes de Atahualpa». Los trabajos basados en el texto de Wachtel tienen que ser, entonces, igualmente sometidos a revisión.

6 Durante la investigación realizada en el Perú en 2009, se ha podido contabilizar unas dieciséis piezas cuyo guión textual había llegado a ser publicado; también se habían publicado nueve descripciones —incluyendo a menudo resúmenes — de representaciones en varios artículos; finalmente, más de veinte representaciones habían sido señaladas sin llegar a ser estudiadas. En anexo (1), se brindará un listado de todo este material, con el objetivo de dar cuenta de la gran diversidad de piezas existentes y fomentar su divulgación. 
con el teatro edificante, la «comedia» española y las representaciones de «moros y cristianos». En el segundo, se dedica al estudio de las piezas bolivianas dadas a conocer por M. Unzueta (1945), C. Balmori (1955), C. Guardia Mayorga (1963) y M. Beyersdorff (2003[1999]) — descartando la versión de Lara por parecerle «una simpática "superchería literaria"»—. De esta manera, P. Duviols evidencia por una parte componentes propiamente católicos en dichas piezas, así como su vinculación con las representaciones de «moros y cristianos», y concluye invitando a revisar la cuestión de su origen:

«Hemos comprobado que, en realidad, esas representaciones no tienen, en su parte medular, origen incaico. Hemos visto que no transmiten ni reflejan la "visión de los vencidos" sino la visión de los vencedores, o mejor dicho, algunas de las visiones de los vencedores» (Duviols, 2000: 240).

De allí la interrogación de B. Ares Queija, al cuestionar la corriente asimilación de las «muertes de Atahualpa» con «la visión de los vencidos»:

«żno tendríamos entonces que tratar de explicar el por qué la contestación del vencido parece estar expresándose en términos del vencedor?» (Ares Queija, 1992: 245).

Ante la necesidad de proponer nuevas vías para el estudio de las «muertes de Atahualpa», se propuso precisamente tratar de averiguar si estas piezas eran expresadas «en términos del vencedor», y en particular si se asimilaban a las representaciones de «moros y cristianos». A primera vista, en efecto, ambos tipos de representaciones emplean esquemas de oposición similares, al hacer enfrentarse, básicamente, un bando de cristianos con un bando de paganos (sean moros o incas). Se recordará rápidamente el argumento básico de los respectivos tipos de piezas.

Las representaciones de «moros y cristianos», también llamadas «danzas», «fiestas», «invenciones» o «relaciones de moros y cristianos», así como «morismas», «morescas» o «embajadas», ponen en escena la victoria simbólica del cristianismo frente al Islam, durante el medioevo español. Las funciones se articulan en torno a un esquema básico de embajada-reto-combate-victoria, a través del cual se enfrentan los cristianos con el enemigo moro, turco o también sarraceno. De manera general, los moros suelen poseer algún objeto cristiano — ciudad, imagen santa, mujer, etc.- , que los españoles van a tratar de recuperar. Por medio de las embajadas, cada bando trata de convencer al otro de su superioridad militar y religiosa, por lo cual acaban desafiándose y combatiendo. La batalla siempre termina con la victoria de los cristianos; los musulmanes reconocen entonces la grandeza de su Dios y suelen convertirse al cristianismo ${ }^{7}$.

Las «muertes de Atahualpa», por su parte, reproducen en cierta medida los acontecimientos de Cajamarca, o sea la conquista del Perú por los españoles, en

7 Las piezas de «moros y cristianos», al igual que las de «la muertes de Atahualpa», pueden adoptar varias formas, desde la danza de comparsa hasta la obra teatral. Los autores del Siglo de Oro también compusieron muchas «comedias» de moros y cristianos, entre otros Lope de Vega. 
particular a través del acto simbólico de la captura y muerte del Inca Atahualpa. Generalmente, los españoles, recién llegados al continente, se ponen en contacto con el Inca a través de sus embajadores, y lo invitan a someterse a su rey y a su Dios. Se organiza luego un encuentro entre los respectivos representantes del poder, durante el cual los cristianos intentan por lo general convertir a Atahualpa. El fracaso de esta empresa desencadena la batalla durante la cual Atahualpa cae preso. Acusado de varios pecados (fratricidio, traición, rebeldía, etc.), se sentencia la ejecución del Inca, el cual generalmente es bautizado antes de morir.

Aunque a primera vista la semejanza entre los dos tipos de representaciones no pase del esquema general de enfrentamiento binario, no podemos dejar de observar que este punto común toca un aspecto propiamente esencial de las dramatizaciones: su estructura. Esta similitud estructural es precisamente lo que nos permite formular la hipótesis del parentesco entre los dos tipos de piezas. Con el propósito de ir más allá en la observación de estas similitudes, emprendimos un estudio comparativo de ambas tradiciones, el cual reproduciremos a continuación. Intentaremos mostrar así que las «muertes de Atahualpa» muy bien podrían ser variantes peruanas de los combates de «moros y cristianos», que de hecho se podrían llamar «incas y cristianos».

Este análisis, se basará principalmente en los trabajos de Demetrio Brisset, quien dedicó una tesis de estado así como varios artículos al estudio literario de las piezas de «moros y cristianos». Reunió para eso un importante corpus, de unos cien textos íntegros y treinta resúmenes de obras realizados por otros investigadores. Por una parte, su análisis pone de relieve la existencia de «contaminaciones» entre las piezas, o sea similitudes en lo que toca a los personajes, a las denominaciones de las piezas y a los santos patronos a los que están dedicadas. Por otra parte, sometiendo su corpus al método de Vladímir Propp para el análisis de la narrativa, D. Brisset extrae una fórmula argumental básica común a todas las variantes. Se verá cuáles son los resultados obtenidos por D. Brisset para «moros y cristianos» y se aplicará su análisis sobre un corpus — más reducido por cierto- de textos de «la muerte de Atahualpa», con el fin de cotejar nuestros resultados con los suyos. De esta manera se podrá observar si las conclusiones de D. Brisset pueden extenderse al presente corpus o si aparecen al contrario diferencias fundamentales que imposibiliten las hipótesis aquí presentadas. Para eso, primero se observará si existen, entre las diferentes «muertes de Atahualpa», contaminaciones similares a las que identifica Brisset entre las morismas. En segundo lugar, se emprenderá la comparación de los dos tipos de piezas a nivel estructural, a partir del análisis del argumento dramático de los distintos guiones. Por último, se comentará varios elementos puntuales que, en este corpus, pueden ser relacionados con las tradicionales morismas: por una parte motivos literarios particulares $y$, por otra parte, aspectos estilísticos y escenográficos relevantes. 
Las representaciones teatrales de «la muerte de Atahualpa»: ¿una herencia de «moros y cristianos»?

\section{ANÁLISIS COMPARATIVO}

\section{1. Las «Contaminaciones»8 entre las distintas obras 9}

\section{1. 1. Denominaciones}

Al cotejar los distintos textos de su corpus, la primera constatación de Demetrio Brisset es que existen numerosas conexiones entre estos. En efecto, aun antes de fijarse en los parlamentos en sí, se evidencian en el paratexto elementos comunes a distintas versiones, tales como las denominaciones - tanto en el título que figura en el texto escrito de una pieza como en el nombre que le dan los habitantes de los pueblos que acogen la función-. D. Brisset nota en particular la repetición de los nombres siguientes: «relaciones; embajadas; soldadesca; danza; batalla; dichos» (Brisset, 2000: s.n.).

Ahora bien, en lo que concierne las «muertes de Atahualpa» se ha podido observar que, de la misma manera, los términos «relación», «embajada» y «baile» aparecen con relevante frecuencia: de las veintiocho denominaciones que se conocen -títulos de guiones y nombres populares confundidos-, doce son términos evocados por D. Brisset.

- Relación (seis casos)

- relato (dos casos)

- relaciones (un caso)

- baile (dos casos)

- embajada (un caso)

Cabe añadir que todos los términos derivados de la palabra «relación» (relación, relaciones, relato) figuran en títulos de libretos de ensayo, o sea que están relacionados con piezas cuyo guión se conoce. De los diecinueve títulos conocidos para las versiones textuales10, nueve contienen el término «relación»o un derivado, o sea casi uno de dos. En cuanto al término «baile», este designa dos piezas de la provincia de Canta (Lima), una cuyo libreto llegó a ser publicado11 y otra cuya representación solamente ha sido señalada12. Por último, el término «embajada» corresponde al título de una representación descrita por Wilfredo Kapsoli (2001) — «La Embajada»—, lo cual sugiere que allí, al igual que en «moros y cristianos», esta acción es central en el desarrollo de la pieza.

8 Empleamos aquí la terminolgía propuesta por D. Brisset.

9 Para este capítulo se tomará en cuenta la casi totalidad del material que se ha podido localizar, o sea dieciséis textos escritos, ocho resúmenes de representaciones y veinte referencias puntuales. Solo se dejará de lado algunas piezas para las cuales no se ha podido obtener los datos que aquí nos interesan. Todos los datos utilizados en este capítulo figuran en el anexo 2 «Cuadro 1», donde se indican las publicaciones correspondientes.

10 Solo disponemos de 16 guiones. Sin embargo, unos llevan varios títulos. Véanse los cuadros anexados.

11 Se trata de la edición de Molina Cuevas (1972).

12 También referida por Molina Cuevas (1972), según J.-P. Husson (1997). 
Los demás títulos tienen que ver con la persona del Inca - gracias a términos como «Atahualpa» o «Inca»— y evocan, en la mayoría de los casos, acciones de la dramatización que lo conciernen. Así se encuentran denominaciones simples tales como «El inca», «Los Ingas» o «El Apu Inca», así como denominaciones más significativas como «Prendimiento y degollación del Inca», «La captura y muerte de Atawalpa» o «La muerte del Inca Atahualpa». Las «relaciones» también cuentan con complementos de títulos similares, como en la «Relación contemporánea de la ejecución de Atahualpa». Otras denominaciones, en cambio, están aisladas, como «La conquista de los españoles» que aparece una sola vez, así como «Relato de Incas e Españoles». En este último caso, se encuentra una oposición binaria al igual que en el nombre genérico de «moros y cristianos». Sin embargo, por lo general, las denominaciones de las piezas tienden a evocar la dramatización de la muerte del Inca más que la oposición de los grupos antagónicos —aunque lo primero sea consecuencia de lo último-.

\section{1. 2. Santos Patronos}

El segundo elemento comentado por D. Brisset a propósito de «moros y cristianos» son los santos patronos a los que se dirigen las fiestas. Observa en efecto que muchas representaciones tienen lugar en honor al mismo patrón. Los más comunes son, por orden de importancia: «San Sebastián (11), San Antonio de Padua (9), San Roque (8), Santa Ana (7), Virgen del Rosario (6), Santa Cruz (6), Apóstol Santiago (6), Virgen de la Cabeza (6)» (Brisset, 2000: s.n.).

No se ha identificado tal fenómeno en el caso de las «muertes de Atahualpa». Si bien algunas representaciones se encuentran dedicadas a patronos citados por D. Brisset, esto ocurre de manera muy puntual: se observa una sola representación en honor a la Virgen del Rosario, otra a Santa Ana y una última a Santiago Apóstol. Al considerar el conjunto de fiestas en las que se puede presenciar «la muerte de Atahualpa», se nota que éstas son muy diversas: son en total treinta y siete representaciones dedicadas a veintinueve santos distintos. Muy pocas celebraciones conciernen entonces a un mismo patrón. Aparecen sin embargo las siguientes correspondencias:

- Inmaculada Concepción (3)

- Natividad de la Virgen (3)

- Virgen de la Asunción (3)

- Santa María Magdalena (2)

- Señor de los Milagros (2)

Por lo demás, solo se tiene conocimiento de fiestas dedicadas a santos aislados. Cabe señalar sin embargo que cerca de la mitad de estas representaciones están dirigidas a la Virgen bajo diversos nombres. Aparecen en efecto fiestas en honor a la Virgen de la Candelaria, Virgen de la Puerta, Nuestra Señora del Monte Carmelo o a la Inmaculada Concepción, las cuales, si bien figuran de manera puntual en nuestras referencias, conciernen todas a la Virgen María. Lo dicho se aplica a 
diecisiete representaciones de un total de treinta y siete, o sea casi una de dos. A este propósito recordemos que la Virgen es, a menudo, el objeto de los cantos de las pallas. Por otra parte, en muchas de las versiones de «moros y cristianos» donde interviene la aparición de algún santo, la Virgen María tiene un particular protagonismo, en igual medida que el Apóstol Santiago.

\section{1. 3. Personajes}

Al tratar el tema de los personajes en «moros y cristiano», D. Brisset establece una distinción entre «personajes genéricos» y «personajes individualizados». La primera categoría incluye denominaciones tales como «General; Rey; Capitán» (Brisset, 2000: s.n.), de las cuales las dos primeras aparecen con relevante frecuencia (veintinueve y veintiséis casos respectivamente, y en cambio dieciséis para «capitán»). En cuanto a los personajes «individualizados», se trata de los que pueden ser identificados por lo menos en la tradición literaria, tales como Carlomagno, Santiago o el rey Fernando en el bando cristiano, y Selim, Balaan o Mahoma del lado moro. Estos personajes son los que predominan en el corpus estudiado por Brisset.

Ahora bien, en las «muertes de Atahualpa» se observa, desde este punto de vista, cierto paralelismo con «moros y cristianos», por lo menos en lo que se refiere a los personajes genéricos. El Inca Atahualpa, quien aparece en todas las piezas sin excepción, es llamado en efecto, de manera común, «Rey Inca», «Rey monarca» o sencillamente «Rey» o «Monarca», y siempre está acompañado por uno o varios generales (Challcochimac, Rumiñahui o Quisquis) y por soldados (sinchis). En el bando español, aparece en todas las versiones un «Pizarro», «Capitán Pizarro» o simplemente «Capitán», acompañado por un embajador, siendo este identificado a veces con Hernando de Soto, Hernando Pizarro o Diego de Almagro, y otras veces designado simplemente por el término genérico «Embajador». Además, en los tres libretos provenientes de Bolivia dentro del presente corpus, figura un «Rey de España». Los personajes esenciales a la representación de los dos poderes en conflicto se encuentran así reunidos en todas las versiones.

El dramatis personae, en la mayoría de las piezas, no se limita evidentemente a este núcleo, sino que aparece una gran cantidad de nombres que figuran en una sola versión de manera aislada. Se puede pensar que se trata, en la mayoría de los casos, de elementos añadidos por las personas a cargo de la representación en una localidad dada13. Algunos de estos elementos pueden aparecer en dos o tres casos solamente, lo cual sugiere que ciertas piezas han podido inspirarse de una misma fuente o tener contactos entre sí — se verá más adelante que en los argumentos también se observan similitudes entre pequeños grupos de piezas-. Por otra

13 Los guiones que se conservan en los pueblos quedan generalmente bajo la protección de quien(es) se encarga(n) de la representación. Generación tras generación, se los vuelve a copiar para que el texto no sufra del deterioro de los documentos. En este proceso, es manifiesto que los copistas añaden su grano a la obra, introducen réplicas, personajes, o quitan otros, etc. Así, los guiones están en constante evolución. 
parte, ciertos personajes vuelven a aparecer en un gran número de obras, lo cual revela que existe un núcleo básico común a todas ellas. De estos personajes, se han apuntado aquellos que aparecen con relevante frecuencia en el conjunto de veinticuatro piezas para las cuales se tenía una información suficiente:

Incas:

- Atahualpa (24)

- Huáscar (11)

- adivino (8): Huayla Huisa (4), Yachaq/Amauta (3), Viso (1)

- General Challcochimac (7)

Españoles:

- Pizarro (22)

- embajador (15): Hernando de Soto (10), Hernando Pizarro (4), anónimo (1)

- Padre Valverde (13)

- intérprete Felipe (13)

Como se verá a través del análisis de los argumentos, estos personajes intervienen en el desarrollo de las acciones esenciales, es decir la lucha por el poder entre incas y españoles, articulada en torno al intento de conversión de aquellos por estos. En efecto, los personajes recurrentes mencionados arriba son representantes del poder y de la religión de los respectivos bandos. Los demás personajes incluidos en el drama no modificarán este núcleo esencial.

El esquema que aparece aquí puede en principio estar relacionado con la lucha de los españoles contra los infieles, tema central de «moros y cristianos». Además, en las «muertes de Atahualpa», se nota la presencia de algunos personajes aislados que sugieren una influencia de las morismas. Así, en la representación de Quinches (Yauyos, Lima), Wilfredo Kapsoli menciona la presencia de una reina en el bando inca (Kapsoli, 2001: 200). Ahora bien, Milena Cáceres, en su estudio sobre «moros y cristianos» en los Andes, refiere la presencia de la Reina Isabel en la representación de Huamantanga, junto con los españoles (Cáceres, 2001: 20). ¿Podría explicarse la presencia de tal personaje en «La muerte de Atahualpa» por la influencia de un sustrato de «moros y cristianos»? En efecto, la reina Isabel la Católica está ligada con la lucha contra los moros, ya que representa, históricamente, al poder que acabó con la dominación árabe en la península ibérica14.

De la misma manera, en la representación de «la muerte de Atahualpa» de Tiahuanaco, estudiada por Jehan Vellard, un informante refiere la presencia de un personaje Ilamado «El turko durano», durante la escenificación que por entonces había desaparecido de las fiestas patronales. Pierre Duviols ve aquí la huella de la temática de «moros y cristianos» (Duviols, 2000: 223). En efecto, el enemigo

14 El historiador Miguel Lafuente Alcántara menciona la visita de la reina a los cristianos durante el sitio de Granada, siendo ella considerada, de manera tradicional, como protectora de los caballeros (Lafuente Alcantara, 1852: 252). 
turco, según se indicó anteriormente, se opone comúnmente a los cristianos en las morismas. Un último detalle sugiere por otra parte la asimilación del Inca Atahualpa a los jefes infieles — sean turcos, moros u otros - de las versiones tradicionales de «moros y cristianos». Se trata del hecho de que en un libreto proveniente de Ámbar (Lima), Atahualpa es designado como «rey indio moro» (Baldoceda, 2007). ¿Podría el Inca, en algún momento, haber sustituido al jefe moro en las representaciones teatrales, después de haber sido confundido con este? Es en todo caso evidente que Atahualpa simboliza de la misma manera la idolatría combatida por los propagadores de la fe cristiana, lo cual se comprobará más adelante a través del análisis de los textos de «La muerte de Atahualpa». Veamos de inmediato la cuestión de la correspondencia argumental entre las dos tradiciones.

\section{2. Comparación de la estructura argumental 15}

A partir de su abundante corpus, D. Brisset lleva a cabo un estudio analítico del argumento de cada versión para definir, recurriendo al método de Vladimir Propp para el análisis de la narrativa, los elementos comunes que constituyen el argumento general de «moros y cristianos». Según sus resultados, dicho argumento podría resumirse con la fórmula siguiente:

«(introducción) / Reto / Súplica / Batalla / (objeto) / prisión» (Bisset, 1993: s.n.)

La «introducción» corresponde a lo que Propp Ilama «situación inicial». Luego viene el «reto», durante el cual ambos bandos defienden su punto de vista, y llegan a provocar la batalla frente a la evidente imposibilidad de conciliación. La «súplica» corresponde a las invocaciones de respectivos grupos para pedir la protección de su dios, para luego entrar en la «batalla». Esta lucha generalmente está motivada por la obtención de algún «objeto» físico o espiritual. Finalmente, el enemigo cae preso.

15 Para este capítulo, no se tomará en cuenta los resúmenes por ser demasiado incompletos en la mayoría de los casos. Se basará exclusivamente en once de los dieciséis guiones conocidos (nueve del Perú y tres de Bolivia). Se han descartado los siguientes documentos:

- Allampushongo Apu Inca o Relación de los Sotos (Tongos) (Medina Susano, 2004), y Cuaderno de relación para vasallos (Tongos) (Iriarte et al., 1985), por ser casi totalmente idénticos a Cuaderno de relación para basallos, que se encuentra más completo por incluir un par de réplicas más que las dos anteriores. Los comentarios que se harán sobre este texto serán asimismo válidos para los precedentes.

- La relación del rey Inca y sus vasallos nombrados (Ámbar) (Baldoceda, 2007) y Relación de las Mojigangas (Huancapón) (Husson, 1997), por ser muy similares a Relación contemporánea de la ejecución de Atahualpa (Manás) (Iriarte et al., 1985). Del mismo modo, las conclusiones relativas a este último texto serán aplicables a los dos primeros.

- La relación (Pachitea) (Mendizábal, 1965), por consistir en la transcripción de los diálogos de una representación durante la cual se oponen una cuadrilla de incas y Francisco Pizarro, casi sin que se desarrolle acción dramática alguna. El texto está principalmente constituido por burlas dirigidas al conquistador. 
En torno a este argumento básico, se articula una dramatización más compleja, cuyas variaciones ha estudiado D. Brisset en función de la aparición de diversos elementos, los cuales a su vez pueden presentar diversas variantes. Así, destacan las acciones siguientes como elementos recurrentes con sus propias variaciones, acciones con las cuales se llega a reconstituir la totalidad de los argumentos de «moros y cristianos»:

- Visión o sueño presagio-aparición sobrenatural

- Negociación-entrega de pliego-reto

- Descanso tras reto-debate interno-juego de azar

- Alianza de ejércitos-milagro

- Herida-curación

- Incidente amoroso-traición

- Batalla por objeto con/sin ayuda sobrenatural

- Muerte-entierro-resurrección

- Prisión o cautiverio-apropiación de atributos-liberación

- Despojo o conversión-premio o recompensa (Brisset, 1993: s.n.)

Las acciones básicas de los argumentos aparecen aquí en su forma esencial, permanente. Los personajes que van a ejecutar dichas acciones, las situaciones particulares dentro de las cuales se van a desencadenar, etc., son al contrario elementos variables, que pueden cambiar de una versión a otra. Si se resume el argumento básico tomando en cuenta únicamente las acciones permanentes y dejando de lado los elementos variables secundarios, se obtiene el siguiente patrón:

Aparece el enemigo con intención de apoderarse de algo $\rightarrow$ Exige su entrega a los héroes y los desafía $\rightarrow$ Súplica de los héroes para obtener la ayuda sobrenatural $\rightarrow$ Batalla por el objeto en litigio, con/sin ayuda sobrenatural $\rightarrow$ Cautiverio del enemigo, que se integra al bando heroico. (Brisset, 1993: s.n.)

A partir de estos resultados, cabe averiguar si los elementos del argumento puestos de relieve por D. Brisset se encuentran asimismo en las «muertes de Atahualpa». ¿Los argumentos de nuestras piezas pueden ser reducidos a ciertas acciones básicas comunes? ¿Estas acciones corresponden con las de «moros y cristianos»? Y la fórmula que resume la estructura esencial de las morismas ¿puede aplicarse a las «muertes de Atahualpa»? Se pondrá ahora a prueba estas hipótesis, a partir del estudio de once de las dieciséis versiones escritas de las que se dispone (véase nota 15 de este texto).

En primer lugar, conviene preguntarse si, dentro del listado de acciones permanentes establecido por D. Brisset, algunas se volvían a encontrar en las «muertes de Atahualpa». Resulta que en cada texto del corpus se encuentra por lo menos una variante de cada una de las diez acciones enunciadas arriba, excepto el tema de la herida y de la curación. A partir de las distintas acciones identificadas, hemos establecido un cuadro que permite observar las variaciones 
Las representaciones teatrales de «la muerte de Atahualpa»: ¿una herencia de «moros y cristianos»?

de cada argumento16. Se verá que dicho cuadro presenta a la vez acciones primarias de las enunciadas por D. Brisset y/o su variante, así como acciones más bien propias de las muertes de Atahualpa cuya frecuencia de aparición quisimos estudiar. Así se puede distinguir las acciones comunes a todas las piezas y las que solamente conciernen grupos determinados, lo cual permitirá definir diferentes tipos de argumentos dentro del corpus.

Así, vemos que todas las «muertes de Atahualpa» comparten las acciones siguientes:

- Embajada de los españoles a los incas

- Petición de sumisión y/o de conversión

- Entrega de un documento escrito (carta y/o Biblia) indescifrable para los incas

- Pérdida de paciencia mutua y reto (por motivos variables)

- Ataque/batalla

- Victoria de los cristianos

- Captura y prisión de Atahualpa

La muerte de Atahualpa no es propiamente explícita en todos los textos: tres de los once textos del corpus no la mencionan, aunque en uno de ellos se le llegue a dictar su sentencia al Inca. Sin embargo sería correcto considerar esta acción como esencial, ya que se la representa, en teoría, en toda puesta en escena17.

Así pues, a partir de estas acciones comunes a todas las piezas, se puede establecer un argumento muy similar al establecido por D. Brisset para «moros y cristianos», aunque con algunos matices. Aparte de que no se ha tomado en cuenta el tema de la ayuda divina por no aparecer sistemáticamente, la diferencia esencial reside en el hecho de que en «moros y cristianos», son los enemigos quienes provocan la lucha y son capturados, mientras que en las «muertes de Atahualpa», son los españoles quienes desencadenan la batalla y los incas quienes son capturados. Se da entonces, en las representaciones andinas, una inversión de la situación héroes/enemigos en relación con las morismas peninsulares. En efecto, si seguimos el resumen de D. Brisset, parece que son los españoles quienes, en las «muertes de Atahualpa», ocupan la posición de los enemigos, ya que son ellos quienes aparecen con la intención de someter al Inca y exigen de él que les obedezca. Este resultado podría servir de argumento para la tesis según la cual las «muertes de Atahualpa» expresarían «la visión de los vencidos». Sin embargo, tal conclusión sería demasiado precipitada ya que, si se mira con atención, los incas sí se convierten en los enemigos en un segundo momento, cuando son vencidos y su jefe cae preso. En esta situación, los héroes son en efecto los españoles, siguiendo el esquema establecido por D. Brisset. ¿Qué significa tal confusión entre

16 Véase el anexo 3 «Cuadro 2» con las acciones primarias en los textos de «la muerte de Atahualpa».

17 Cabe señalar a este propósito que los libretos de ensayo contienen casi exclusivamente los parlamentos que los actores tienen que memorizar y muy pocas indicaciones escénicas. Así, acciones teatrales tales como la batalla entre incas y españoles y la ejecución de Atahualpa, que son más bien gestuales, no siempre están explícitamente indicadas. No es de dudar, sin embargo, de que estén escenificadas durante las representaciones, ya que por otra parte están evocadas en todas las descripciones de las que disponemos. 
enemigos y héroes? ¿Acaso no se trata de una simple adaptación del esquema dramático a la realidad de la conquista del Perú? En efecto, la diferencia esencial que aparece aquí se encuentra asimismo en la historia de los países respectivos cuyas tradiciones estamos estudiando: mientras que en la península ibérica se designa la lucha de los cristianos contra los moros como «Reconquista» luego de una invasión, en el Perú fueron los españoles quienes invadieron el territorio inca. Las «muertes de Atahualpa» respetan en eso el desarrollo histórico de la Conquista. Convendría pues reformular el resumen de D. Brisset adaptándolo a esta variante americana de batalla simbólica. Así, el argumento de las «muertes de Atahualpa» podría resumirse como sigue:

Aparece el héroe con intención de apoderarse de algo $\rightarrow$ Exige su entrega a los enemigos y los desafía $\rightarrow$ El rechazo del enemigo se percibe como una provocación, lo cual desencadena una batalla por el objeto en litigio $\rightarrow$ Cautiverio (y muerte) del enemigo.

Este argumento básico se puede completar si se toman en cuenta acciones que, si bien no figuran en la totalidad del corpus, aparecen sin embargo con una frecuencia significativa:

- Situación inicial (6): en seis de los once textos, se encuentra una situación inicial dentro de la cual se evoca el contexto anterior a la invasión española, tanto en el bando español como en el bando inca (tres casos), o solamente en este último (tres casos). Así se representa, por ejemplo, la investidura de Pizarro por el rey de España por un lado, y las guerras fratricidas entre Huáscar y Atahualpa por otro.

- Visiones, presagios (7): se mencionan con frecuencia visiones o presagios que anuncian al Inca su próxima derrota, a través de un sueño o de señales naturales tales como la desaparición de los astros o el silencio de las huacas, o sea de los ídolos. Este motivo se encuentra en seis obras al principio, como predicción de la conquista española, y en otra al final, cuando Atahualpa les pregunta a sus adivinos si va a morir.

- Embajada inca (6): después de la embajada española, puede intervenir una embajada inca que contribuye por lo general a desencadenar el enfrentamiento. En efecto, en las tres versiones bolivianas, los emisarios incas traen de vuelta — sin haberlo entendido - el Requerimiento por el cual se ordena la sumisión de Atahualpa18, lo cual será percibido por los cristianos como una afrenta suficiente para justificar el ataque. En otras tres piezas, esta embajada le ofrece al intérprete (Felipe, Felipillo, Kusichimpu) la oportunidad de modificar las palabras de los emisarios: transforma sus mensajes de bienvenida en amenazas.

- Traición del intérprete (4): tal como se acaba de mencionar, este elemento interviene en tres textos durante la embajada inca. En otra obra, Felipe visita a

18 El Requerimiento es un texto jurídico, redactado en 1512 por Juan López de Palacios Rubios, que los conquistadores españoles tenían que leer en su primer encuentro con los pueblos autóctonos del Nuevo Mundo. Se explica en él, entre otras cosas, cómo el Papa donó esos territorios a los reyes de España, los cuales tenían entonces legítima autoridad para exigir la sumisión de sus pobladores. Los indios, así informados de la situación (si es que la entendían), eran considerados como rebeldes si no se sometían. 
Atahualpa y lo enoja contándole mentiras sobre las intenciones de Pizarro, lo cual contribuirá a provocar la batalla.

- Prédica (7): muy a menudo, cuando ya han tenido lugar las embajadas y la tensión entre ambos grupos alcanza un hito, los españoles envían a un cura (Valverde) para que trate de convertir a Atahualpa. Será el fracaso de este intento lo que desencadenará la batalla, en cinco casos debido a que Atahualpa tira al suelo la Biblia que le han dado, y en tres casos porque su incomprensión lo convierte en un provocador. Cabe por otra parte destacar la importancia del tema de la conversión del idólatra en todo el corpus.

- Rescate (8): en casi todas las obras, Atahualpa propone grandes cantidades de oro y plata por su libertad. Algunas veces los españoles aceptan pero acaban ejecutándolo a pesar de todo, y otras veces no parecen interesados por el trato, estando más preocupados por su conversión que por sus riquezas. Sin embargo, se puede relacionar este tema con el del despojo evocado por D. Brisset.

- Bautismo (5): finalmente, en casi la mitad de las piezas, se bautiza a Atahualpa antes de que sea ejecutado. Este acto le permite al padre Valverde, en una ocasión, exhortar al público a que siga su ejemplo. El hecho de que el Inca muera cristiano parece constituir una victoria para los españoles, quienes cumplen de esta manera con su misión. En la mayoría de las piezas, en efecto, Atahualpa es visto como un idólatra — se verá más adelante a través de qué recursos-, y su sumisión al cristianismo - y a los cristianos - constituye el objeto que tratan de obtener los españoles.

A través de las acciones que se han evocado, se ha evidenciado, en las «muertes de Atahualpa», una gran cantidad de acciones elementales de «moros y cristianos». Quedan sin embargo otros elementos que no se han comentado por no aparecer en un número significativo de textos, pero que constituyen asimismo rasgos de similitud entre las dos tradiciones: aparecen en efecto en algunas piezas debates internos (3) entre incas y/o entre españoles, así como invocaciones de la protección de la Virgen por los españoles —e incluso por Huáscar en la versión de Manás-, y a veces súplicas dirigidas por las incas a sus propias divinidades (3), o intentos de negociación entre los vencedores y su cautivo (3).

Si se retoma ahora la fórmula establecida por D. Brisset para el argumento general de «moros y cristianos», se verá en qué medida se puede aplicar a las «muertes de Atahualpa». Brisset daba la fórmula siguiente:

«(introducción) / Reto / Súplica / Batalla / (objeto) / prisión« (1993: s.n.)

La introducción, o situación inicial, existe, tal como ha sido visto, en seis de los once textos. El reto, a través del cual los dos grupos se desafían, tiene lugar en todas las piezas sin excepción, a veces de manera indirecta a través de la traición del intérprete y/o del hecho de que Atahualpa tire la Biblia al suelo, entre otros motivos19. La invocación de los dioses no está, por su parte, lo suficientemente

${ }^{19}$ En Tongos, Atahualpa tira el alcohol que le propone Soto, además de una carta. En Chilia, rompe un cristal. En una de las versiones de Carhuamayo («El Tamboy»), el hecho de que Atahualpa se 
presente como para poder considerarla como acción esencial. Al contrario, la batalla, consecuencia del reto, es un elemento central de la dramatización. El objeto de la batalla no es aquí material sino espiritual, ya que es la sumisión — política y religiosa - del Inca lo que se busca en todas las versiones sin excepción. Finalmente, la captura de Atahualpa es también esencial en el conjunto del corpus, y significa la obtención del objeto deseado por las españoles, a veces junto con el bautismo. Se podría entonces reformular así la síntesis de los argumentos:

(Introducción) / Reto / (Prédica) / Batalla / Objeto-Prisión

Las «muertes de Atahualpa», en su estructura misma, podrían entonces perfectamente constituir una variante de «moros y cristianos». Los estudios llevados a cabo por Milena Cáceres sobre los motivos literarios de una versión peruana de «moros y cristianos» la llevan a las mismas conclusiones. Ella refiere en efecto que la cadena de motivos que ha establecido para El Ave María del Rosario de Huamantanga podría asimismo aplicarse a «otras versiones de Ave María, a las versiones de Carlomagno y los Doce Pares de Francia, e inclusive a obras teatrales aparentemente más lejanas, como la Danza del Inca» (Cáceres, 2001: 44).

\section{3. Elementos aislados significativos}

\section{3. 1. Motivos literarios}

Dejando ya de lado las correspondencias estructurales fundamentales y si uno se centra en los textos de manera individual, puede verse que algunos de estos pueden ser agrupados en función de la variación de los elementos secundarios de su argumento. Los motivos aislados así puestos de relieve merecen atención. Se destaca, en particular, el parentesco de las tres piezas bolivianas incluidas en el corpus, o sea las versiones de Oruro, Santa Lucía y San Pedro de Challacollo20, que parecen ser variantes de un mismo drama. Presentan en efecto las mismas particularidades: la situación inicial, en los tres casos, refiere cómo Pizarro fue encargado por el rey de España de someter al monarca inca, además de evocar la situación de los incas antes de la Conquista. Se encuentra luego el motivo del presagio de la llegada de los españoles, y la tradicional embajada, aquí a cargo de Diego de Almagro o de un anónimo «embajador». Aquí es donde interviene una primera situación característica: los embajadores no llegan a entenderse ya

niegue a someterse se ve como una provocación. Finalmente, en las versiones bolivianas, se trata del retorno del Requerimiento incomprendido.

20 Todo parece indicar que la llamada versión de Santa Lucía en realidad sería la de San Pedro de Buenavista. Según parece, hubo algún tipo de confusión entre quienes estudiaron estas obras (véanse al respecto Beyersdorff, 2003 e Itier, 2001: 105-106). Elegimos sin embargo seguir recurriendo a esta denominación, primero porque esa es la que aparece en las publicaciones que la difundieron, y segundo para que no haya confusión con la pieza de San Pedro de Challacollo. Acerca del texto de Oruro, véase Balmori, 1955; Santa Lucía: Meneses, 1987b; San Pedro de Challacollo (de aquí en adelante «Challacollo»): Beyerdorff, 2003. 
que no tienen intérprete. Mientras que en todas las otras piezas la petición de sumisión formulada por los españoles está expresada oralmente y traducida por el intérprete, en las versiones bolivianas el embajador español le entrega una carta a su homólogo inca, carta que constituye el Requerimiento. Sucede entonces un episodio durante el cual todos los personajes incas intentan descifrar, sin lograrlo, los símbolos de la escritura21. El emisario inca, entonces, vuelve ante el embajador español para obtener una explicación oral. Pero el retorno de la carta es percibido como un rechazo de sumisión de parte de Atahualpa, o sea una provocación. En estas tres obras pues, lo que permite esta variante del reto es la falta de intérprete.

Sin embargo, luego aparecen diferencias entre las tres obras: mientras que en Oruro y Santa Lucía la batalla tiene lugar justo después de la fracasada embajada inca, en Challacollo interviene un intento de prédica emprendida por el padre Valverde frente a Atahualpa, esta vez con la ayuda del intérprete Felipillo. Este no vuelve a intervenir en ningún otro momento de la obra, por lo cual se deduce que esta, al igual que las dos primeras, fue originalmente producida sin incluir al personaje del intérprete, sin lo cual el papel de la incomprensión en el desencadenamiento de la batalla no tendría justificación. Ahora bien, el episodio de la prédica interviene en casi todas las piezas peruanas (seis de ocho). ¿Puede entonces considerarse la introducción del episodio de la prédica en Challacollo como influencia de las obras peruanas? Todo parece en efecto indicar que no formaba parte del drama original en Bolivia.

Entre las tres variantes bolivianas, se encuentra otra divergencia: es esta vez la llamada versión de Santa Lucía la que se distingue de las demás, por la ausencia de un episodio específicamente boliviano. En Oruro y Challacollo, en efecto, asistimos a una sorprendente escena en la cual los incas derrotan a Almagro y sus soldados, antes de que tenga lugar la batalla central22. Tienen entonces lugar, en estas versiones, dos enfrentamientos: en el primero vencen los incas, en el segundo los españoles. Ahora bien, en cierto tipo de representaciones de «moros y cristianos», se observa de la misma manera una primera victoria de los moros sobre los cristianos, antes de que, en una segunda batalla, se invierta la situación. Según refiere D. Brisset, Guillermo Gustavino, en su clasificación de las fiestas de «moros y cristianos», establece una categoría especial para este tipo de representaciones, que se encuentran en la zona de la Alpujarra (Andalucía) y presentan las siguientes características:

«[Representaciones] rurales, sencillez de recursos y medios, acción dramática en dos partes: vencen los moros en la primera y recobran el castillo o la imagen perdida los cristianos en la segunda, terminando con

21 Una escena similar también tiene lugar en las obras peruanas, cuando Atahualpa intenta descifrar la Biblia, aunque no con tanto detenimiento como en Bolivia.

22 En la versión de Oruro encontramos la siguiente indicación escénica: «Almagro es derrotado» (Balmori, 1955: 94; en Challacollo: «Almagro es derrotado por Huayla Huiksa» (Beyersdorff, 2003 [1999]: 323). 
la conversión de los musulmanes» (Brisset, 1993: s.n., citando a Guillermo Gustavino, 1969).

Al no ser la derrota de Almagro frente a los incas un acontecimiento histórico ni tampoco un tema difundido por la literatura, la introducción de ese elemento en «la muerte de Atahualpa» podría explicarse por la influencia de «moros y cristianos».

Finalmente, las tres versiones bolivianas comparten otro elemento propio, relacionado con esa situación inicial característica de la que ya hemos hablado. En efecto, después de la ejecución de Atahualpa, Pizarro vuelve aquí a presentarse ante el rey de España, para dar cuenta del cumplimiento de su misión y para entregarle «la cabeza y la corona del rey Inca»23. La reacción del rey de España es inmediata: condena el regicidio y manda matar a Pizarro, e incluso a toda su descendencia en Oruro y Challacollo. Se encuentra en este episodio la huella de dos motivos literarios difundidos en la literatura española: «el enojo del rey» y «la cabeza cortada». El primero se vuelve a encontrar en la representación de «moros y cristianos» de Huamantanga, El Ave María del Rosario, donde «Fernando el Católico se enoja con Garcilazo por haber ido a campear sin su permiso contra el moro más aguerrido y [...] lo castiga mandándolo al calabozo» (Cáceres, 2001: 50). Según refiere Milena Cáceres, se trata de un motivo característico de la literatura española. En cuanto al segundo motivo, María Soledad Carrasco escribe lo siguiente acerca de su gran popularidad:

«La crítica ha destacado el "Efecto especial: la cabeza cortada", que refleja un motivo folklórico que está muy presente en el romancero vulgar del siglo $\mathrm{XVI}$ y entra en el romancero morisco nuevo como jactanciosa promesa de trofeo que el moro retador ofrece a su dama» (Carrasco, 2003: 32).

La introducción de semejantes motivos en las «muertes de Atahualpa» parece entonces corresponder perfectamente a las normas literarias españolas. Cabe destacar por otra parte que si bien el motivo del enojo del rey solo aparece en las tres versiones bolivianas, el de la decapitación figura al contrario en casi todo el corpus. En efecto, en todos nuestros textos excepto en los de Carhuamayo - $\mathrm{O}$ sea nueve de once-, el Inca es ejecutado por decapitación. Tal fenómeno se encuentra además en gran cantidad de representaciones de las que solo se tienen descripciones. Quienes han tratado el tema del valor simbólico de las «muertes de Atahualpa» suelen considerar este hecho como consecuencia de la asimilación, en el pensamiento colectivo andino, de Atahualpa a Túpac Amaru, siendo ambos el «último Inca» en distintos momentos de la historia de la dinastía. Cabe recordar a este propósito los famosos dibujos de Felipe Guaman Poma de Ayala, donde se representan las muertes de los respectivos Incas de igual manera24. Sin negar

23 Dice Pizarro en Oruro: «Aquí traigo la cabeza y la corona del Rey Inca de los Indios» (Balmori, 1955: 101); en Challacollo: «Aquí traigo la cabeza y la corona del Rey Inca soberano de los Incas del Perú» (Beyersdorff, 2003 [1999]: 350). En Santa Lucía, es el embajador quien le dice a Pizarro antes de su partida: «aquí está la cabeza y la corona de ese hombre rebelde» (Meneses, 1987b: 40).

24 Cf. Guaman Poma (2005: 297 y 347). Ambos dibujos están reproducidos en el anexo 4. 
la posibilidad de tal asimilación, cabe sin embargo preguntarse si la tradición literaria española, introducida por los conquistadores, no podría haber tenido algún papel en la aparición de este fenómeno. En efecto, se puede pensar que la popularidad del tema de «la cabeza cortada» en la literatura de conquista, en un contexto donde la realidad histórica ofrecía además ejemplos de decapitación famosos y con simbolismo fuerte, pudo contribuir a favorecer dicha interpretación del pasado. La asimilación de la muerte de Atahualpa con la de Túpac Amaru podría entonces haber sido influida por una interpretación literaria del pasado. Nos parece entonces que, más allá de la importancia que tuvo la muerte de Túpac Amaru en el pensamiento colectivo andino, la literatura española probablemente participó de la constitución del motivo de la decapitación de Atahualpa, que aparece en la literatura de conquista en general, y entonces probablemente en las fuentes de las «muertes de Atahualpa».

Se ha visto, pues, que las tres piezas bolivianas presentan elementos propios que pueden relacionarse con la tradición literaria española y en particular con «moros y cristianos». Este hecho sugiere que proceden sin duda de una misma fuente, compuesta según las modalidades de la literatura de conquista. De la misma manera, se distinguen otros grupos de textos donde aparecen algunos motivos particulares asimismo identificables con la tradición occidental. Así por ejemplo, los textos procedentes de Llamellín y de Manás - y entonces los de Huancapón y Ámbar - presentan una situación inicial singular: mientras está en Baños del Inca con su séquito, Atahualpa se entera de que su hermano Huáscar se ha fugado con una o dos de sus ñustas, por lo cual lo manda detener y matar. En Manás, Atahualpa se da cuenta de que dos pallas han desaparecido, y su adivino Yachac le revela entonces que fueron raptadas por Huáscar. Atahualpa ordena entonces su muerte y sus generales le traen la corona del rey derrotado. En Llamellín en cambio, Huáscar rapta a una sola mujer. Atahualpa ordena asimismo su ejecución y sus generales le traen su cabeza.

Estos elementos recuerdan, en primer lugar, lo dicho anteriormente acerca del motivo de la decapitación. En efecto, mientras que en los textos bolivianos Pizarro le trae a su rey la corona y la cabeza del Inca, aquí los generales de Atahualpa le traen o la cabeza o la corona de su hermano. En segundo lugar, el tema de la mujer raptada también corresponde a cierto tipo de representaciones de «moros y cristianos». Según refiere D. Brisset, el motivo de «la cristiana cautiva» fue, durante varios siglos, muy popular en el romancero, que inspiró en gran medida las comedias de «moros y cristianos». Brisset pone además de relieve la particular importancia, en estas tradiciones, de la legendaria historia del tributo de cien doncellas que los cristianos tenían que pagar cada año al moro Mauregato, rey de Córdoba (Brisset, 2007: s.n.). La batalla de Clavijo, con la cual se puso fin a este tratado, constituye asimismo una variante de «moros y cristianos», desarrollada por ejemplo por Lope de la Vega en «Las famosas asturianas». En las «muertes de Atahualpa» de Llamellín y de Manás, el episodio del rapto de la/s princesa/s por Huáscar parece constituir una intriga interna dentro del conjunto de la obra. Así, en Llamellín y en Manás, encontramos un primer enredo, que concluye con la muerte de Huáscar — enemigo de Atahualpa-, y luego una segunda intriga que 
termina con la muerte de Atahualpa —enemigo de los españoles_-, presentando cada uno correspondencias con «moros y cristianos».

Por otra parte, las piezas de Llamellín y Manás pueden ser relacionadas con las de Pomabamba y Chilia, con las que comparten el motivo de la traición del intérprete. Ya hemos visto que el tema de la traición está evocado por D. Brisset como uno de los elementos permanentes de «moros y cristianos». Cabe añadir al respecto que este es también un tema central en la «Historia de Carlomagno y los doce pares de Francia», en particular en el episodio de la derrota de Roldán. Según refiere el relato, Carlomagno, a través de sus embajadores, negocia la paz con el Califa Marsil. Sin embargo el emisario Ganelón, mandado frente al rey moro para sellar el pacto, está celoso de Roldán por haber sido nombrado este al mando de la guardia imperial, y anima entonces a Marsil a que traicione a Carlomagno lanzando el ataque contra las tropas de Roldán a pesar del tratado. En las «muertes de Atahualpa» — en los cuatro textos mencionados—, Atahualpa parece estar dispuesto, en un principio, a recibir a los españoles con amistad y manda a sus embajadores a que les lleven este mensaje. La traición de Felipe tendrá lugar o durante la traducción de las palabras de los emisarios, provocando así el enojo de Pizarro sin que lo entiendan los incas, o durante la embajada del intérprete frente a Atahualpa, a quien convencerá para que ataque a los españoles.

Las variaciones más notables entre los distintos argumentos de las «muertes de Atahualpa» resultan entonces corresponder a elementos que también se encuentran en «moros y cristianos» y en la literatura española en general. De la misma manera, dichas variaciones se encuentran relacionadas con los distintos «tipos» de morismas, definidos en función de la estructura argumental por Brisset o, según se ha evocado, en función de las áreas geográficas por Guillermo Gustavino. Así pues, algunas de las «muertes de Atahualpa» siguen el modelo de las morismas de la Alpujarra, según la clasificación de G. Gustavino -las tres versiones bolivianas—, mientras que otras se acercan más bien al ciclo de Carlomagno —el grupo Llamelín-Manás-Pomabamba-Chilia-. Además, el argumento interno que se observa en la situación inicial de las piezas de Llamellín y Manás corresponde al tipo «cautiverio y rescate de la imagen», establecido por Brisset, que incluye el tema de la doncella cautiva (Brisset, 2007: s.n.).

\section{3. 2. Aspectos estilísticos}

Cabe subrayar de la misma manera la presencia, dentro del cuerpo de los textos, de ciertos términos y fórmulas que remiten a recursos estilísticos así como a temas literarios ampliamente difundidos en la literatura medieval española. Se identifica por ejemplo la figura del enemigo religioso a través del Inca, quien está designado como un bárbaro idolatra, al igual que el musulmán en «moros y cristianos». Tal asimilación se expresa de manera explícita en las siguientes expresiones refiriéndose a Atahualpa: «Ah, bárbaro rey gentil» (Manás), «Oh valeroso infiel» y «este bárbaro infiel» (Tongos) (Iriarte et al., 1985: 110, 127 y 128 respectivamente); «este bárbaro monarca»(Pomabamba) (Kapsoli, 2001: 
216); «el bárbaro» (Llamellín) (Iriarte et al., 1985: 21). De la misma manera, a los emisarios del Inca se les llama «bárbaros indios» (Manás), y el Tawantinsuyu es designado como «este imperio del demonio, este reino de supersticiones e idolatrías» (Manás) (Iriarte et al., 1985: 108 y 109). Otros elementos expresan las creencias idolátricas del Inca, oponiéndose a la religión a la cual los españoles tratan de convertirlo. Así por ejemplo, en Pomabamba, Atahualpa compara a su adivino con el dios Pachacámac (Kapsoli, 2001: 223). Asimismo, en Oruro, el Inca invoca al Sol de la misma manera como los españoles se encomiendan a la Virgen: «vamos a implorar Mallku Sol, para que nos dé un poco de esfuerzo» (Balmori, 1955: 94). Finalmente, en Manás y en Tauca, la derrota de los incas está anunciada por la desaparición del Sol y de la Luna, a los cuales las pallas dirigen sus cantos: «Mi padre sol, mi madre luna, [...] / no nos dejen todavía en la oscuridad» 25 . A través de estos términos, la derrota del Inca frente a los españoles se percibe como consecuencia del abandono de sus dioses, lo cual hace de estas «muertes de Atahualpa», tal como «moros y cristianos», representaciones de la superioridad del cristianismo.

Se nota por otra parte la presencia, en varios textos, de un vocabulario épico por el cual se expresan temas propios del ideal caballeresco difundido por la literatura medieval española —en particular los temas del amor cortés y del valor en el combate- . Así encontramos en las piezas de Pomabamba y de Llamellín —entre las cuales, sea dicho de paso, se encuentran importantes similitudes textuales-, esta significativa arenga:

«Vigilancias de un heroico pecho no admiten ningún descanso» (Kapsoli, 2001: 216)26.

En otro momento, en un parlamento pronunciado por Pizarro, los españoles quedan presentados como herederos del modelo de valor romano y glorificados a través de una succesión de epítetos meliorativos:

«Arrogantes españoles hijos del invencible Marte [...]. Valerosos capitanes, hijos de valor romano que entre marciales estruendos que pasmó nuestra braveza, cuyos pechos generosos pueblan estos mares iAl Arma!» (Kapsoli, 2001: 227 y 230)27.

En Pomabamba todavía, Pizarro alaba en estos términos la fuerza de su brazo:

«Monarca altivo en lid nos veremos; tu arrogancia y soberbia por mis brazos y este acero serán humillado y destruido» (Kapsoli, 2001: 222).

Otro ejemplo significativo se encuentra en el libreto de Chilia —exclusivamente en español—; se trata de una arenga pronunciada por Pizarro, dentro de la cual

25 Texto de Manás, traducción inédita de César Itier. Encontramos fragmentos similares en el texto de Tauca, por ejemplo: «Padre Sol, Madre Luna, ipor qué se desaparecen ustedes?» (Meneses, 1987a: 121).

26 En Llamelín: «Vigilancia de un heroico pecho, no admites ningún descanso» (Iriarte et al., 1985: 21).

27 En Llamellín: «Valerosos adelides hijos de un bene < ra > ble marte cuya < pedio > generoso pueblan [aquestos mares] al arma» (Iriarte et al., 1985: 31). Estos textos han sufrido un evidente deterioro. 
toma como referencia a Aníbal, famoso héroe cartaginés y modelo de valor militar, y a Roldán, uno de los doce pares de Francia, protagonista de la lucha contra el moro al lado de Carlomagno:

«Atención fuertes soldados, valor, ánimo y coraje

Resolución al combate no sus ánimos desmayen,

Mostrar en esta ocasión Anibales y Roldanes

Y al ser tan <asinaldos> y otros caballeros tales» (Iriarte 1985: 41)28.

Cabe preguntarse si la introducción de semejantes referencias en una obra posiblemente destinada a feligreses — en Chilia se conserva el libreto de ensayo en la sacristía de la Iglesia (Iriarte et al., 1985: 40)— supone que el público esté familiarizado con las correspondientes tradiciones literarias. Algunos datos de la historia colonial del Perú nos indican al respecto que los evangelizadores, en varios casos, enseñaron a los indios sus composiciones literarias, e incluso llegaron a traducirlas a las lenguas indígenas 29 , lo cual no imposibilita esta sugerencia. Sin saber si el público primitivo de las «muertes de Atahualpa» estaba o no familiarizado con la literatura medieval española — de hecho no se sabe quién era este público-, parece aquí evidente que ciertos textos del corpus — por lo menos- se inspiraron directamente en ella.

\section{3. 3. Elementos escenográficos}

Llama la atención, respecto a lo anteriormente dicho, el hecho de que se haga mención en casi todos los textos del corpus, y de manera repetitiva, de un «castillo», término que designa, en las piezas de «moros y cristianos», una estructura de madera que representa la ciudad fuerte a mano de los moros, objeto de su batalla contra los cristianos. Todo parece indicar que las representaciones de «la muerte de Atahualpa», de la misma manera, suelen organizarse en torno a un «castillo» - estructura de madera realzada - que simboliza el centro del poder inca, y que los españoles tratan de tomar para asentar su dominación. Así por ejemplo, en Llamellín, Pizarro ordena: «iapoderados del castillo! » (Iriarte et al., 1985: 21); en Santa Lucía, es el rey de España quien ordena: «marchad al castillo» (Meneses, 1987b: 26); otro ejemplo se ve en Chilia, donde uno de sus generales le advierte a Atahualpa: «vendrán a poseer tu castillo» (Iriarte et al., 1985: 43). Además, el término en castellano incluso figura tal cual en los diálogos en quechua, como por ejemplo en Llamellín, cuando Huáscar explica que se ha fugado a la ciudad de Tumbes con la princesa que le ha raptado a su hermano: «Kay yuraq markapi

28 También este documento muestra deterioro. Se trata del texto más antiguo que se conoce: según está apuntado en el libreto, se trata de una copia de 1890.

29 El propósito aquí no es detenerse sobre este tema. Solo se citará, a modo de referencia, a Acosta: «También han puesto [los nuestros] en su lengua composiciones y tonadas nuestras, como de octavas, y canciones de romances, de redondillas, y es maravilla cuán bien las toman los indios, y cuanto gustan» (Acosta, 2002: 416). Sobre este tema véanse Estenssorro, 1992; Armas, 1953; para el caso de México: Ricard, 1932; 1933 en particular. 
castillota rurachini $\gg 30$ (Iriarte et al., 1985: 19)31. La influencia de las tradiciones medievales españolas parece, aquí también, evidente.

Finalmente, se referirá rápidamente a algunos apuntes acerca de los elementos de escenografía evocados en descripciones de representaciones realizadas por algunos investigadores. Aparecen, en este material, detalles que remiten a representaciones de tipo «moros y cristianos» referidas en documentos de los siglos XVI y XVII. Esperando tener la oportunidad de desarrollar este tema más adelante, se limitará aquí a evocar algunas coincidencias que pueden terminar de convencer de la necesidad de dirigir las investigaciones sobre el desarrollo y la adaptación de las tradiciones españolas introducidas en el Perú, principalmente alrededor del siglo XVII, para tratar de entender el origen de las «muertes de Atahualpa».

A título de ejemplo, evocaremos el hecho de que en la descripción de una función de «La muerte de Atahualpa» en Otuzco en 1949, Richard Scheadel menciona la presencia de un músico que toca la flauta y el tambor - elemento, por cierto, muy común en los ambientes festivos andinos-. El hecho es que este mismo músico aparece en documentos iconográficos de la época colonial que representan danzas relacionadas con las morismas: por una parte en una acuarela del Obispo Jaime Martínez Compañón titulada Doce Pares de Francia (Martínez Compañón, 1994 [1978]: f. 144), y por otra parte en un dibujo de Felipe Guaman Poma de Ayala donde se ve cómo «los hijos de principales han de danzar delante del Sacramento» (Guaman Poma, 2005: 639)32.

Por otra parte, en la representación de Quinches — cuya descripción, realizada por Teófanos Michuy, está referida por Wilfredo Kapsoli-, los españoles están vestidos como soldados del siglo XVI:

«Los españoles van uniformados con vestimenta militar de la época de la conquista: corazas, cascos relucientes, grandes espadas, largas barbas y espuelas brillantes» (Kapsoli, 2001: 200).

30 «En esta blanca tierra mandé hacer un castillo». Transliteración y traducción del quechua por César Itier (texto inédito). Se agradece al Profesor Itier la comunicación de estos documentos.

31 Además, el «castillo» aparece en una abundante documentación colonial. En un dibujo de Guaman Poma figurando una batalla entre chilenos y españoles por la ciudad de Santa Cruz de Chile, la mención «castillo» figura debajo de la imagen (cf. anexo 5). Este dibujo, por lo demás, parece representar un tipo de escenificación teatral más que un enfrentamiento real. Un motivo designado como «castillo» o «torreón» por los especialistas figura también con mucha frecuencia en escenas de combates representadas en qeros (vasos ceremoniales). Véanse al respecto los ejemplos reproducidos en el anexo 6 , en particular $6 \mathrm{~b}$ y $6 \mathrm{c}$ donde se distingue claramente la representación de una torre o «torreón».

32 Cf. los anexos 7 y 8 . Los atributos de los personajes del mencionado dibujo de Guaman Poma permiten relacionar su baile con las morismas: tienen cascabeles en los pies, palos en la mano y llevan túnicas y máscaras con bigote. La vestimenta ha sido identificada por Ramón Mujica Pinilla como «túnicas y máscaras de moros» (Mujica Pinilla, 2007: 173). Los cascabeles se vuelven a encontrar en la acuarela de los Doce Pares de Francia de Martínez Compañón y en una descripción realizada por Diego de Esquivel de un baile, aparentemente morisco, que presenciara durante el Corpus Cristi en Cuzco en 1700 (Esquivel, 1980: 183). Finalmente los palos que manejan son típicos de las «danzas de palos», bailes que corresponden a una forma primitiva de morisma. 
Esta descripción coincide, por una parte, con la representación que hace Martínez Compañón de los pares de Francia en la acuarela que acabamos de mencionar, y por otra parte con la descripción que ofrece Diego Esquivel de un baile presenciado durante el Corpus Cristi en Cuzco en 170033. Así, los cristianos, sean pares de Francia o generales españoles, se representan siempre con atributos similares, tanto en las «muertes de Atahualpa» como en las morismas. Esta ausencia de distinción parece lógica si se considera que en los dos casos se trata de un mismo personaje en una dimensión genérica: los cristianos. Su oponente siempre es algún enemigo religioso: moro, turco, judío, o también azteca, maya o inca, etc. La identidad del grupo enemigo es en realidad un elemento variable, secundario, que no nos parece un rasgo pertinente para la caracterización de nuestras representaciones en oposición a las de «moros y cristianos» en su dimensión simbólica.

\section{CONCLUSIONES}

Tras el análisis que se ha llevado a cabo, parece pertinente considerar las «muertes de Atahualpa» como una variante de «moros y cristianos» cuyos elementos han sido adaptados en relación con la realidad histórica americana. Por una parte se ha visto, a través del estudio de las contaminaciones entre las piezas, que ambos tipos de representaciones son a menudo designados por los mismos términos, y que sus personajes presentan las mismas funciones. Luego se ha mostrado que ambos comparten una misma estructura básica, y que el bando inca muy bien pudo sustituir al moro en las morismas. Finalmente, varios elementos aislados identificables en los textos y su escenificación indican que el sustrato de «moros y cristianos» dejó huellas en las «muertes de Atahualpa». Por su función simbólica, ambos tipos de piezas, que se podrían llamar «moros y cristianos» e «incas y cristianos», se presentan como variantes de un mismo esquema que opone cualquier religión no-cristiana al cristianismo.

Este es un hecho determinante a la hora de reflexionar sobre el contexto de la aparición de las «muertes de Atahualpa». Su origen, pues, no tiene que buscarse en la literatura oral indígena inmediata a la Conquista, sino en las producciones coloniales conformes con la normativa literaria española. Desde este punto de vista, las informaciones históricas acerca de representaciones de la muerte del Inca durante fiestas coloniales seguramente pueden ofrecernos pistas para entender su función primera. Claro está, en efecto, que si bien en la actualidad las «muertes de Atahualpa» pueden volverse vehículo de reinvindicación por parte de los comuneros indígenas que las celebran, el hecho de que estén conformes con las normas literarias españolas medievales y que aparezcan en

\footnotetext{
${ }^{33}$ «Son los danzantes unos indios con máscaras, vestidos a la española con ropones de rasos, guarnecidos de pasamanos de plata y oro, rapazejos, o franjas [...]. Llevan gorra con plumajes o torreones de plata: un bastón en la mano y botas, en los pies con cascabeles. Van continuamente danzando al son de un atambor, con que le sigue otro, haciendo a cada dos golpes acelerados una breve pausa, o compás, y tocando al mismo tiempo una delgada flauta» (Esquivel, 1980: 183).
} 
contextos cívico-religiosos supone que, en la época colonial, muy bien pudieron ser producciones destinadas a la glorificación de la Corona y de Dios. Al respecto, de hecho, varios comentaristas presentan «la muerte de Atahualpa» no como la expresión de la «visión de los vencidos» sino como una glorificación de la Conquista 34 , tal como lo eran las representaciones de «moros y cristianos» que aparecieron en las fiestas cívico-religiosas por lo menos en el siglo XVII y que siguen representándose hasta el día de hoy35. Varias preguntas surgen entonces: ¿cómo y cuándo las representaciones de «moros y cristianos» dieron paso a las «muertes de Atahualpa»? ¿Quiénes fueron los instigadores de ese proceso? ¿Qué función, qué interés podía revestir la introducción de una «muerte de Atahualpa» dentro de las fiestas cívico-religiosas? ¿Quiénes tenían tales intereses, y quiénes pudieron producir o mandar producir tales piezas? La demostración del parentesco entre las «muertes de Atahualpa» y «moros y cristianos» podrá ayudar a resolver estos y otros interrogantes al convencer de la necesidad de orientar las investigaciones hacia nuevos rumbos.

\section{Referencias citadas}

ACOSTA, J. de, 2002 - Historia natural y moral de las indias, 492 pp.; Madrid: Dastin. Edición de J. Alcina Franch.

ARES QUEIJA, B., 1992 - Representaciones dramáticas de la conquista: el pasado al servicio del presente. Revista de Indias, 52 (195/196): 231-250.

ARMAS MEDINA, F., 1953 - Cristianización del Perú (1532-1600), 638 pp.; Sevilla: Escuela de Estudios Hipano-Americanos.

ARZÁNS de ORSUA y VELA, B., 1965 - Historia de la villa imperial de Potosí (L. Hanke \& G. Mendoza, eds.), 3 vols.; Providence: Brown University Press.

BALDOCEDA, A., 2007 - Códice de la relación del rey inca y sus vasallos nombrados, 119 pp.; Lima: [s. n.].

BALMORI, C. H., 1955 - La conquista de los españoles y el teatro indígena americano, 119 pp.; Tucumán: Universidad Nacional de Tucumán.

BEYERSDORFF, M., 2003 [1999] - Historia y drama ritual en los Andes bolivianos, 395 pp.; La Paz: Plural.

34 Uriel García refería, en 1938, que en esas representaciones «danzarines y comparsas celebraban la conquista como un "rescate"» (Uriel García, 1938: s. n.). En el siglo XVII, Fransico del Castillo (El ciego de la Merced) compuso una obra de temática similar a las «muertes de Atahualpa» —aunque con mayor grado de elaboración - titulada La conquista de los españoles, que probablemente se representó en 1748 dentro de las celebraciones en honor al rey Fernando VI. Aparece lo siguiente en el manuscrito de la obra: «Fiesta que en celebridad de la coronación de Nuestro Católico Monarca Don Fernando Sexto, dispuso el gremio de los naturales de esta ciudad de Lima manifestando en ella su cordial, reverente obsequio» (Castillo, 1996: 219).

35 La primera referencia explícita a «moros y cristianos» en el Perú se remonta al siglo XVIII (se trata de la acuarela de Martínez Compañón titulada Doce pares de Francia. Martínez, 1994 [1978]: II, f144). Sin embargo, ya en el siglo XVII aparecen tipos de representaciones aparentemente asimilables con «moros y cristianos» (véase por ejemplo Zuidema, 1991). Finalmente, Milena Cáceres dedicó un estudio a esas representaciones en la actualidad (Cáceres, 2001). 
BRISSET, D., 1993 - Clasificación de los «moros y cristianos». Gazeta de Antropología, (edición electrónica), $\mathbf{n} \cdot{ }^{\mathbf{0}} \mathbf{1 0}$.

BRISSET, D., 2000 - Fiestas hispanas de moros y cristianos. Historia y significados. Gazeta de Antropología, (edición electrónica), n. 17.

BRISSET, D., 2007 - Antropología visual de la simbología del cautiverio femenino, Gazeta de Antroplogía, (edición electrónica), $\mathbf{n} .^{\circ} 23$.

CÁCERES VALDERRAMA, M., 2001 - La fiesta de moros y cristianos en el Perú, 163 pp.; París: Indigo \& Côté-Femme.

CARRASCO URGOITI, M. S., 2003 - La escenificación del triunfo del cristianismo en la comedia. In: Moros y Cristianos (M. Albert-Llorca \& J. A. González Alcantud, eds.): 25-44; Toulouse/Granada: Presses Universitaires du Mirail/Diputación de Granada.

CASTILLO, Fray F. del, 1996 - Obra completa. Introducción, transcripción y notas por C. A. Debarbieri, 1093 pp.; Lima: [s.n.].

CASTILLO CANO, L., 1971 - La fiesta del Rey Inca y su aplicación en la Escuela Ayavirina; Lima: Centro de Arte Folklórico del Perú 'Rosa Mercedes Ayarza de Morales'.

CHAVEZ DE PAZ, D., 2005 - Dos dramas coloniales quechua-castellano sobre la prisión y muerte del inca Atahualpa en el Perú. In: Entre tradición e innovación. Cinco siglos de literatura amerindia (J.-P. Husson, ed.): 175-189; Lima: PUCP.

CORNEJO POLAR, A., 1990 - El comienzo de la heterogeneidad en las literaturas andinas: voz y letra en el diálogo de Cajamarca. Revista de crítica literaria latinoamericana, XVII (33): 155-207.

DUVIOLS, P., 1999 - La representación bilingüe de «La muerte de Atahualpa» en Manás (Cajatambo) y sus fuentes literarias. Histórica, XXIII (2): 367-392.

DUVIOLS, P., 2000 - Las representaciones andinas de «La muerte de Atahualpa». Sus orígenes culturales y sus fuentes. In: La formación de la cultura virreinal, I (K. Kohut \& S. V. Rose, eds.): 213-248; Madrid / Frankfurt: Iberoamericana / Vervuert.

ESQUIVEL Y NAVIA, D. de, 1980 - Noticias cronológicas de la gran ciudad del Cuzco (F. Denegri Luna, ed.), 2 vols.; Lima: Fundación Augusto Wiese.

ESTENSSORO FUCHS, J. C., 1992 - Los bailes de los indios y el proyecto colonial. Revista Andina, 10 (2): 353-389.

FELICIANO, W., 2000 - La captura y muerte de Atawalpa, Sapallanga, Perú, 1998. Gestos, 29: 143-147.

FREZIER, A., 1716 - Relation du voyage de la mer du sud aux côtes du Chily et du Pérou, 1712, 1713 et 1714, 300 pp.; París: Jean-Geoffroy Nyon.

FLORES OCHOA, J. A., KUON ARCE, E. \& SAMANEZ ARGUMEDO, R., 1998 - Qeros, 333 рp.; Lima: Banco de Crédito del Perú.

GONZÁLEZ CARRÉ, E. \& RIVERA PINEDA, F., 1982 - La muerte del Inca en Santa Ana de Tusi. Bulletin de l'Institut Français d'Études Andines, 11 (1-2): 19-36.

GUAMAN POMA DE AYALA, F., 2005 - Nueva corónica y buen gobierno (F. Pease G. Y., ed.), 3 vols.; Lima: Fondo de Cultura Económica.

GUARDIA MAYORGA, C. [Kusi Paukar], 1963 - Atawalpa wañusqanta. Inkakuna Rimasqan, [in. ${ }^{\circ}$ ?]: 23-36.

GUSTAVINO, G., 1969 - Las fiestas de moros y cristianos y su problemática, 25 pp.; Madrid: Consejo Superior de Investigaciones Científicas.

HUSSON, J.-P., 1997 - Une survivance du théâtre des Incas: le cycle de la mort d'Atawallpa; París: Université Paris III. Tesis de estado.

IRIARTE BRENNER, F., RAVINES, R. \& AHÓN OLGUÍN, M., 1985 - Dramas coloniales del Perú actual, 134 pp.; Lima: Universidad Inca Garcilaso de la Vega. IV Congreso 
Las representaciones teatrales de «la muerte de Atahualpa»: ¿una herencia de «moros y cristianos»?

peruano del hombre y la cultura andina.

ITIER, C., 2001 - ¿Visión de los vencidos o falsificación? Datación y autoría de la Tragedia de la muerte de Atahuallpa. Bulletin de I'Institut Français d'Études Andines, 30 (1): 103-121.

ITIER, C., 2009 - La Tragedia de la muerte de Atahuallpa de Jesús Lara, historia de una superchería literaria. Anuario de Estudios Bolivianos, Archivísticos y Bibliográficos, 15: $215-229$.

KAPSOLI, W., 2001 - La muerte del Rey Inca en las danzas populares y La Relación de Pomabamba. In: La memoria de los ancestros (L. Millones \& W. Kapsoli, eds.): 191237; Lima: Universidad Ricardo Palma.

LAFUENTE ALCANTARA, M., 1852 - Historia de Granada comprendiendo la de sus cuatro provincias [... ], 2 vols.; París: Baudry Librería europea.

LARA, J., 1957 - Tragedia del fin de Atawallpa. Atau Wallpaj p'uchukakuyninpa wankan, 195 pp.; Cochabamba: Imprenta Universitaria.

LIEBSCHER, V., 1986 - La iconografía de los qeros, 106 pp.; Lima: Herrera Editores.

MARTÍNEZ COMPAÑÓN, B. J., 1978-1994 - La obra del obispo Martínez de Compañón sobre Trujillo del Perú en el siglo XVIII, 13 vols.; Madrid: Ed. Cultura hispánica del Centro iberoamericano de cooperación.

MEDINA SUSANO, C., 2004 - Escenificación de la conquista del Perú en la fiesta de San Pedro de Tongos, 113 pp.; Lima: Biblioteca Nacional del Perú, Fondo Editorial.

MENDIZÁBAL LOSACK, E., 1965 - La fiesta en pachitea andina. Folklore Americano, 13: 141-227.

MENESES, T., 1987a - La muerte de Atahualpa. Drama quechua de autor anónimo, 169 pp.; Lima: Universidad Nacional Mayor de San Marcos.

MENESES, T., 1987b - Debate de Incas. Kuntur, Perú en la cultura, 5: 25-40.

MILLONES, L., 1988 - El Inca por la Coya. Historia de un drama popular en los Andes peruanos, 106 pp.; Lima: Fundación Friedrich Ebert.

MILLONES, L., 1998 - Dioses familiares. Festivales populares en el Perú contemporáneo, 291 pp.; Lima: Congreso del Perú.

MOLINA CUEVAS, C., 1972 - El baile de los Ingas en el pueblo de Canta; Lima: Escuela Nacional de Arte Folklórico 'Rosa Mercedes Ayarza de Morales'.

MUJICA PINILLA, R., 2007 - Apuntes sobre moros y turcos en el imaginario andino virreinal. Anuario de Historia de la Iglesia, 16: 169-180.

OLESZKIEWICZ, M., 1992 - El ciclo de la muerte de Atahualpa. De la fiesta popular a la representación teatral. Allpanchis, 23 (39): 185-220.

RICARD, R., 1932 - Contribution à l'étude des Fêtes de 'Moros y Cristianos' au Mexique. Journal de la Société des Américanistes, 24: 51-84.

RICARD, R., 1933 - La conquête spirituelle du Mexique : essai sur l'apostolat et les méthodes missionnaires des Ordres Mendiants en Nouvelle-Espagne de 1523-24 à 1572, 404 pp.; París: Institut d'Ethnologie.

SCHEADEL, R., 1952 - La representación de la muerte de Atahualpa en la fiesta de la Virgen de la Puerta de Otuzco. Cultura Peruana, 12 (53), [s.n.].

UNZUETA, M., 1945 - Valle; Cochabamba: La Época.

URIEL GARCÍA, J., 1938 - Las Danzas indígenas del Perú como elementos teatrales en las épocas incaica y colonial. Revista del Instituto Nacional de Estudios del Teatro, IV (7). 
VELLARD, J.-A. \& MERINO, M., 1954 - Bailes folklóricos del Altiplano. Travaux de I'Institut Français d'Etudes Andines, 4: 59-132.

WACHTEL, N., 1971 - La vision des vaincus : les Indiens du Pérou devant la conquête espagnole, 1530-1570, 395 pp.; Paris: Gallimard.

ZUIDEMA, T., 1991 - Batallas rituales en el Cuzco colonial. In: Cultures et Sociétés. Andes et Méso-Amérique. Mélanges en hommage à Pierre Duviols (R. Thiercelin, ed.): 811834; Aix-en-Provence: Publications de I'Université de Provence. 
Las representaciones teatrales de «la muerte de Atahualpa»: ¿una herencia de «moros y cristianos»?

\section{Anexo 1. Listado de material relativo a las «muertes de Atahualpa»}

Se indican la procedencia geográfica del material y las correspondientes publicaciones en las que se puede encontrar.

\section{Textos}

Bolivia:

San Pedro de Challacollo (Cercado, Oruro) (Beyersdorff, 2003 [1999])

Oruro (Oruro) (Balmori, 1955)

San Pedro de Buenavista (Charcas, Potosí) (Guardia Mayorga, 1963, y Meneses, 1987b)

[Santa Lucía de Cliza (Cliza, Cochabamba) (no publicado pero confundido con el de Buenavista)]

[Toco (Cliza, Cochabamba) (Unzueta, 1945, fragmentos)]

Perú:

Manás (Cajatambo, Lima) (Iriarte et al., 1985)

Huancapón (Cajatambo, Lima) (Husson, 1997)

Ámbar (Huaura, Lima) (Baldoceda, 2007)

Tongos (Huaura, Lima) (Iriarte et al., 1985 y Medina Susano, 2004)

Canta (Canta, Lima) (Molina Cuevas, 1972)

Ayavirí (Yauyos, Lima) (Castillo Cano, 1971)

Llamellín (Antonio Raimondi, Ancash) (Iriarte et al., 1985)

Pomabamba (Pomabamba, Ancash) (Kapsoli, 2001)

Tauca (Pallasca, Ancash) (Meneses, 1987a)

Chilia (Pataz, La Libertad) (Iriarte et al., 1985)

Panao (Pachitea, Huánuco) (Mendizábal, 1965)

Carhuamayo (Junín, Junín) (Millones, 1988; 1998)

\section{Descripciones}

Bolivia:

Tiahuanaco (Ingavi, La Paz) (Vellard \& Merino, 1954)

Corocoro (¿Pacajes?, La Paz) (Vellard \& Merino, 1954)

Perú:

Viscas (Canta, Lima) (Kapsoli, 2001)

Quinches (Yauyos, Lima) (Kapsoli, 2001) 
Sapallanga 1 (Huancayo, Junín) (Feliciano, 2000)

Sapallanga 2 (Huancayo, Junín) (Chávez de Paz, 2005)

Otuzco (Otuzco, La Libertad) (Sheadel, 1952)

Piscobamba (Pomabamba, Ancash) (Kapsoli, 2001)

Santa Ana de Tusi (Daniel A. Carrión, Pasco) (González Carré \& Rivera Pineda, 1982)

\section{Otras representaciones señaladas (Perú)}

Andajes (Oyón, Lima) (Iriarte et al., 1985)

Mallay (idem)

Naván (idem)

Oyón (idem)

Pachangara (idem)

Cajatambo (Cajatambo, Lima) (Iriarte, 1985)

Copa (idem)

Gorgor (idem)

Nava (idem)

Utcas (idem)

Huaros (Canta, Lima) (Molina Cuevas, 1972)

Pampacocha (¿Canta?) (Molina Cuevas, 1972)

Culluhuay (¿Canta?) (Molina Cuevas, 1972)

Huañec (Yauyos, Lima) (Castillo Cano, 1971)

Huampará (idem)

Pilas (idem)

Roca (Boloñesi, Ancash) (Oleszkiewicz, 1992)

¿Aquía? (Boloñesi, Ancash) (Oleszkiewicz, 1992)

Llata (Huamalies, Huánuco) (Kapsoli, 2001)

Baños (Lauricocha, Huánuco) (Oleszkiewicz, 1992)

Patoga (Huánuco) (Oleszkiewicz, 1992)

Huancayo (Huancayo, Junín) (Vellard \& Merino, 1954) 
Las representaciones teatrales de «la muerte de Atahualpa»: ¿una herencia de «moros y cristianos»?

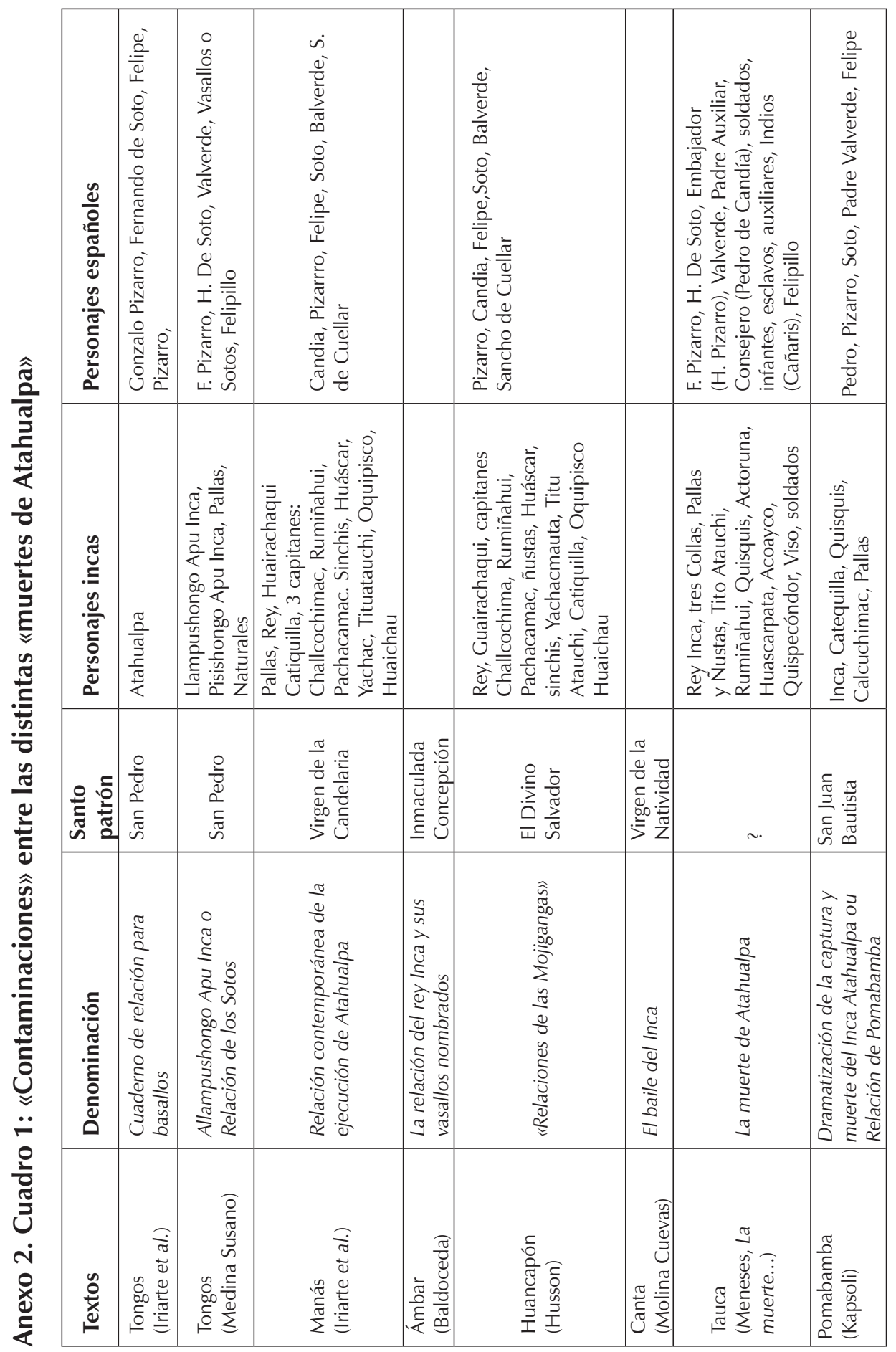


Marine Bruinaud

\begin{tabular}{|c|c|c|c|c|c|c|c|c|}
\hline 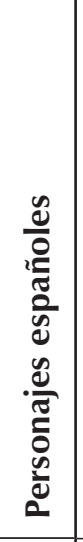 & 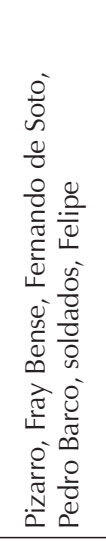 & 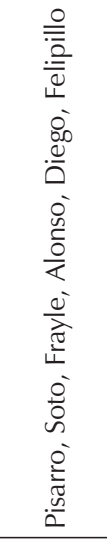 & 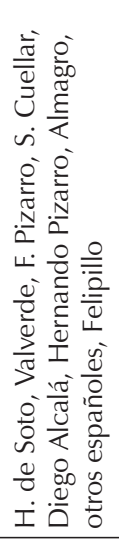 & 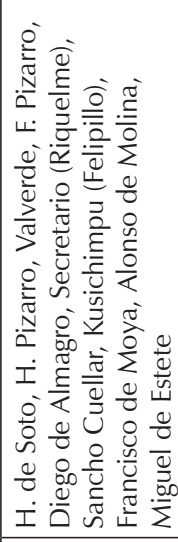 & $\begin{array}{l}\frac{0}{\pi} \\
\frac{\pi}{2} \\
\frac{N}{2}\end{array}$ & 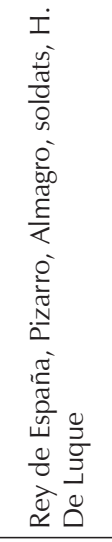 & 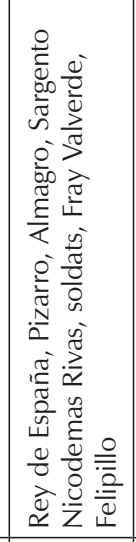 & 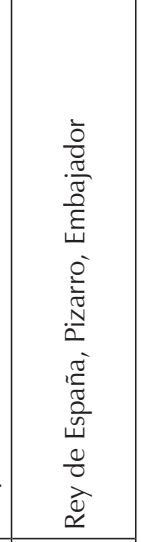 \\
\hline 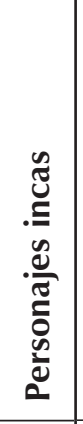 & 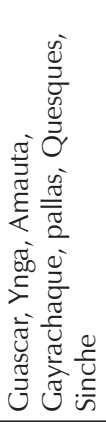 & 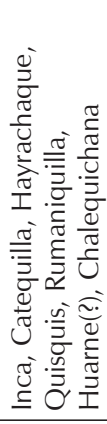 & 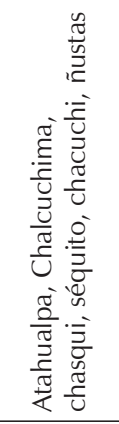 & 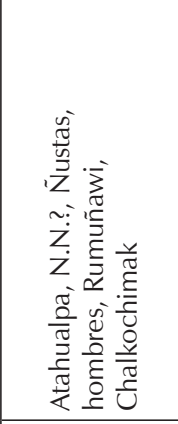 & 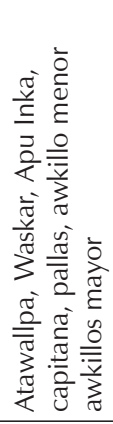 & 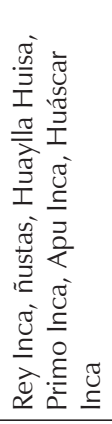 & 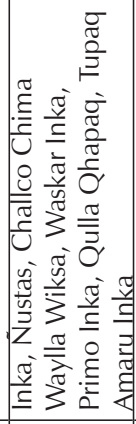 & 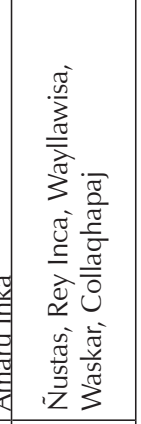 \\
\hline 虽 & 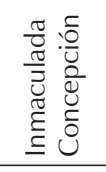 & 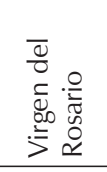 & 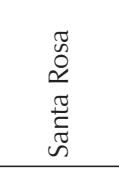 & 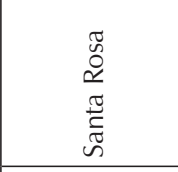 & 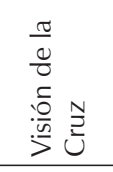 & 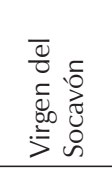 & 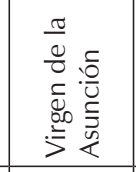 & \\
\hline 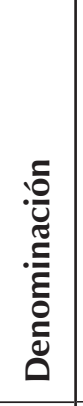 & 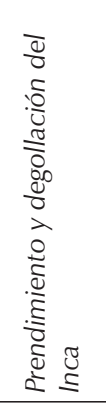 & $\begin{array}{l}\tilde{\Xi} \\
\stackrel{0}{0} \\
\tilde{0}\end{array}$ & 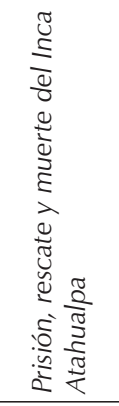 & $\begin{array}{l}\text { ठे } \\
\text { है } \\
\frac{0}{\omega} \\
\end{array}$ & 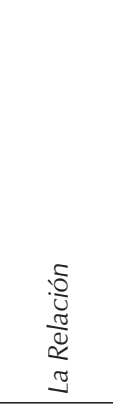 & 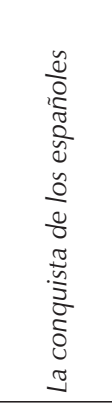 & 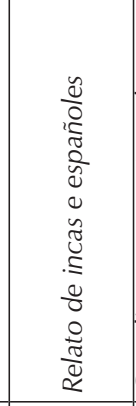 & 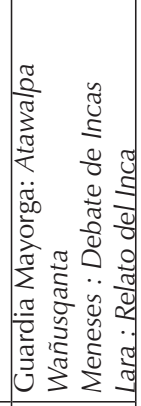 \\
\hline$\frac{\mathscr{c}}{\frac{0}{x}}$ & 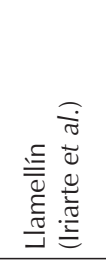 & 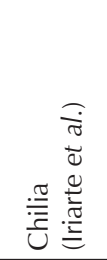 & 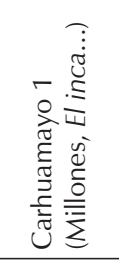 & 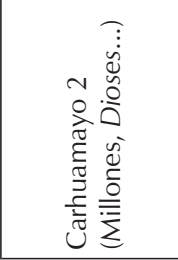 & 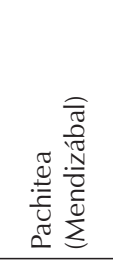 & 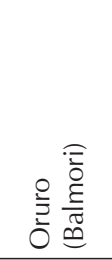 & 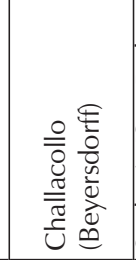 & 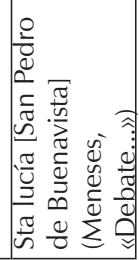 \\
\hline
\end{tabular}




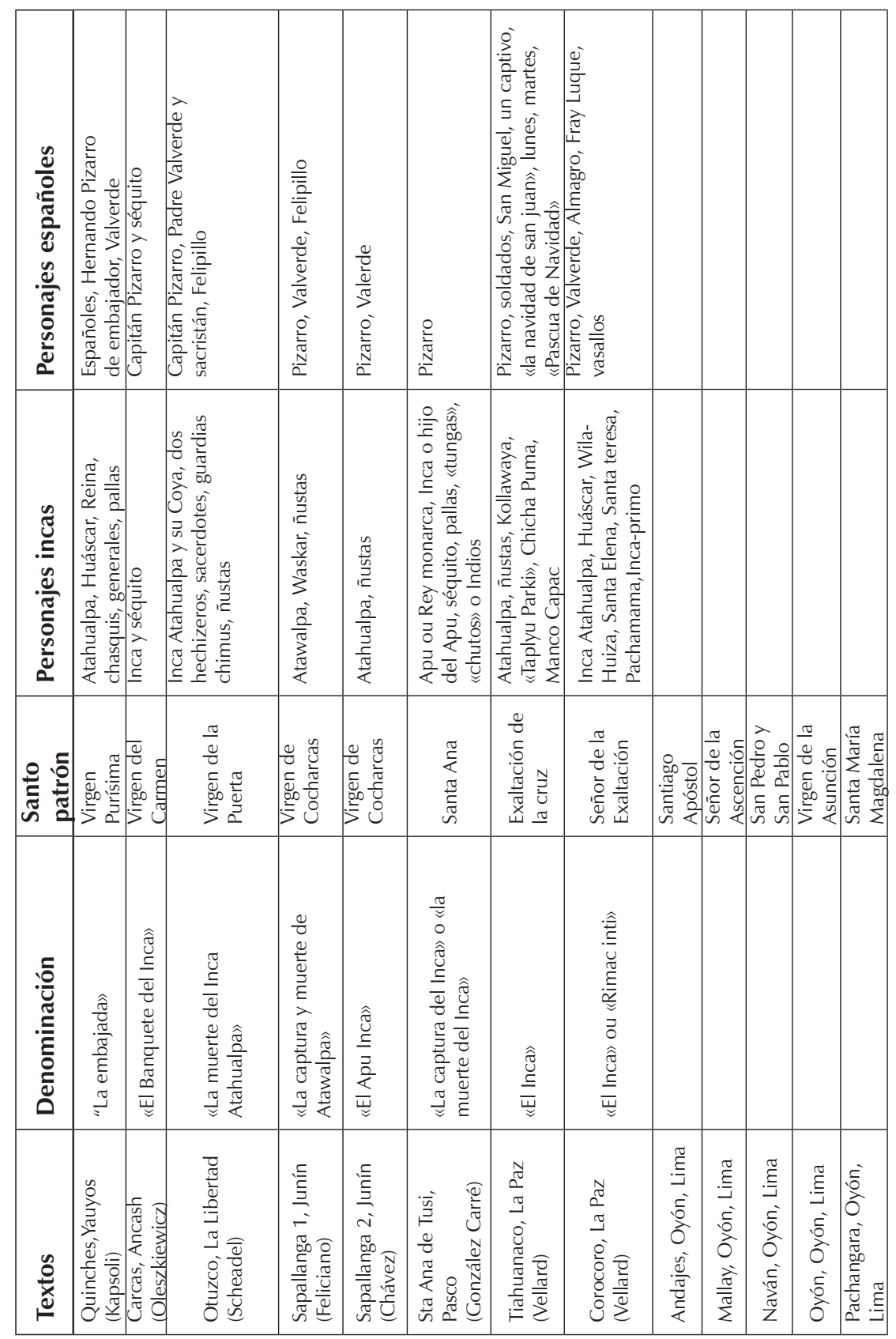




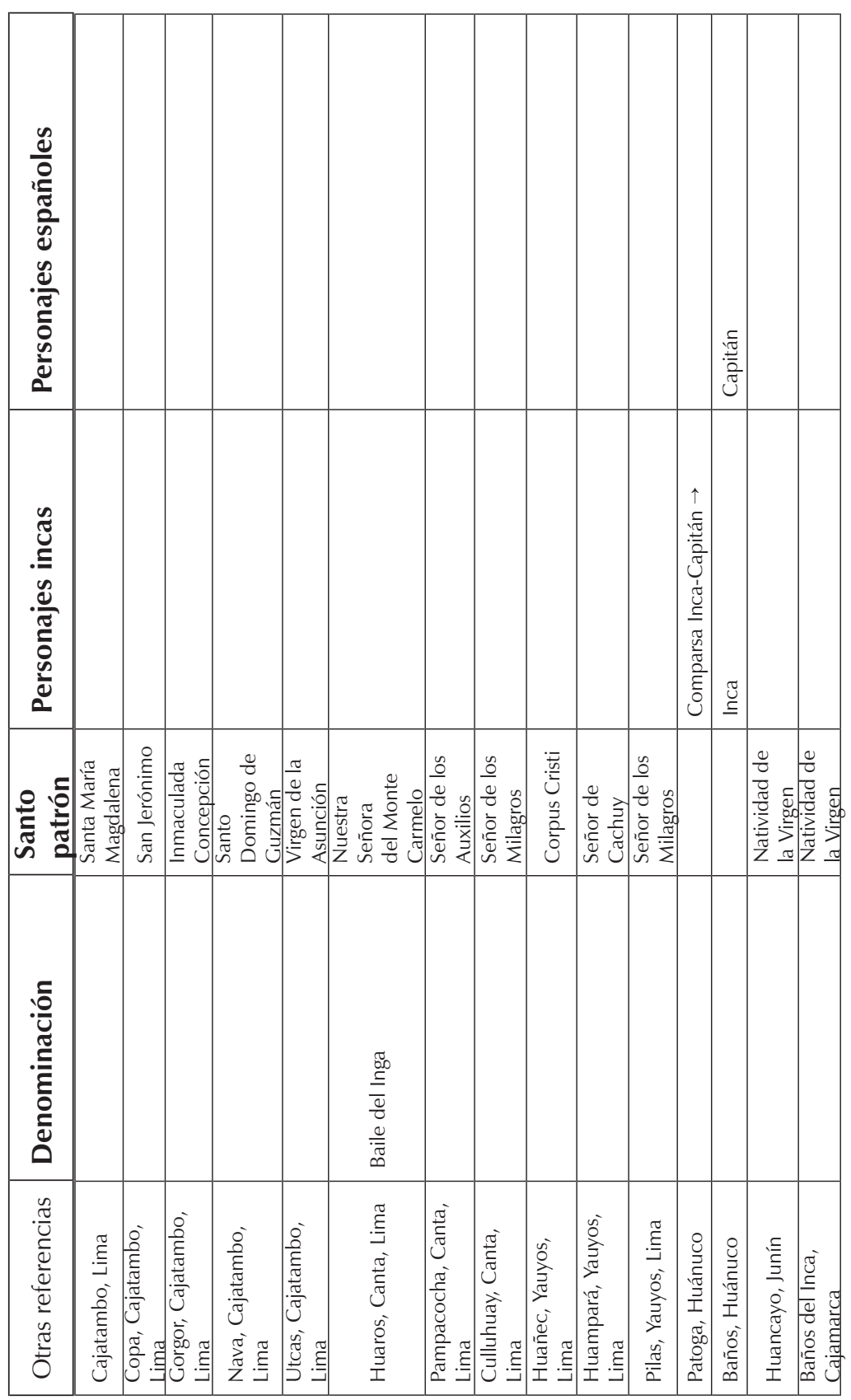


Las representaciones teatrales de «la muerte de Atahualpa»: ¿una herencia de «moros y cristianos»?

\begin{tabular}{|c|c|c|c|c|c|c|c|c|c|c|c|}
\hline :气 & & $\times$ & $x \mid \times$ & & $\times$ & & & & & & \\
\hline$\frac{\tilde{\Xi}}{\stackrel{\Xi}{3}}$ & & & $\times x$ & & & & & & $<$ & & \\
\hline $\begin{array}{l}\frac{0}{\pi} \\
\frac{0}{0} \\
0 .\end{array}$ & & & $\times$ & & $x$ & & & & & & \\
\hline$\frac{\stackrel{Q}{\mathscr{U}}}{\simeq}$ & & 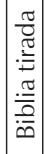 & 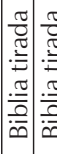 & 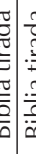 & $\frac{3}{2}$ & 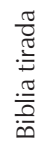 & 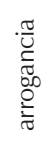 & & & 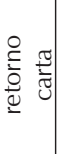 & 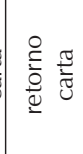 \\
\hline
\end{tabular}

\begin{tabular}{|c|c|c|c|c|c|c|c|c|c|}
\hline 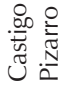 & & & & & & & $\times$ & $\times$ & $\times$ \\
\hline 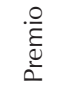 & & & & 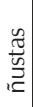 & $\frac{\stackrel{\mathscr{U}}{\omega}}{\frac{\vec{\varepsilon}}{\varepsilon}}$ & 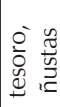 & & & \\
\hline 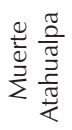 & $\times \times$ & $x$ & 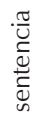 & & $\times$ & $x$ & $\times$ & $x$ & $x$ \\
\hline 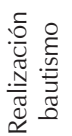 & $x$ & & & & $\times$ & $\times$ & & & $\times$ \\
\hline
\end{tabular}

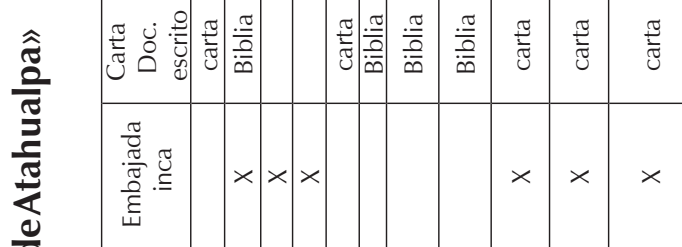

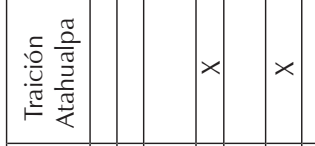

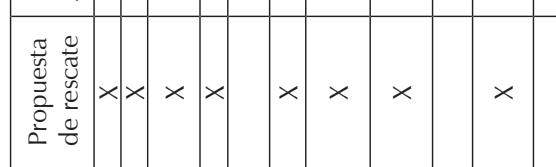

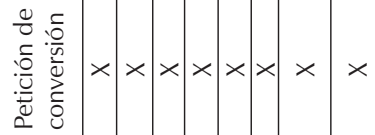

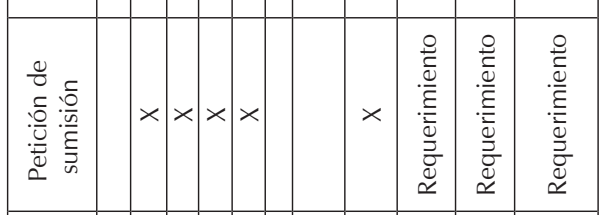

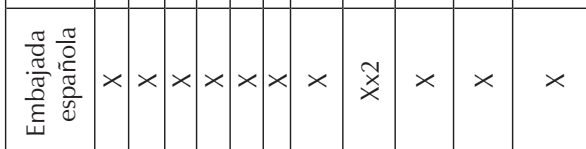

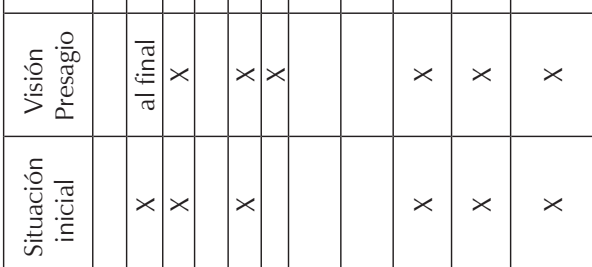

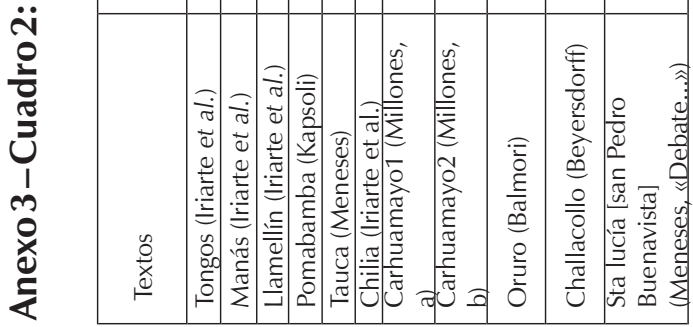

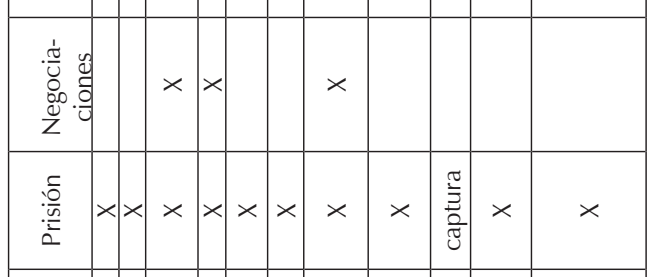

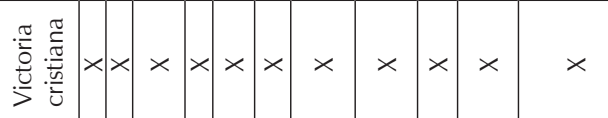

\begin{tabular}{|c|c|c|c|c|c|c|c|c|c|c|}
\hline 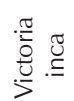 & & & & & & & & $\times$ & & $\times$ \\
\hline $\begin{array}{l}\frac{\pi}{\bar{N}} \\
\frac{\sqrt[\pi]{\mathbb{N}}}{\infty}\end{array}$ & $\frac{\stackrel{0}{2}}{\frac{7}{\pi}}$ & $\times$ & $\times>$ & & $\begin{array}{c}0 \\
+ \\
+\end{array}$ & $\times$ & $\times$ & $\begin{array}{l}\frac{0}{\partial} \\
\frac{\vec{\sigma}}{v} \\
\frac{\pi}{0}\end{array}$ & $\times$ & $\tilde{x}$ \\
\hline
\end{tabular}

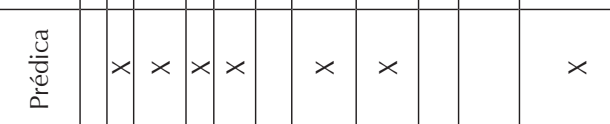

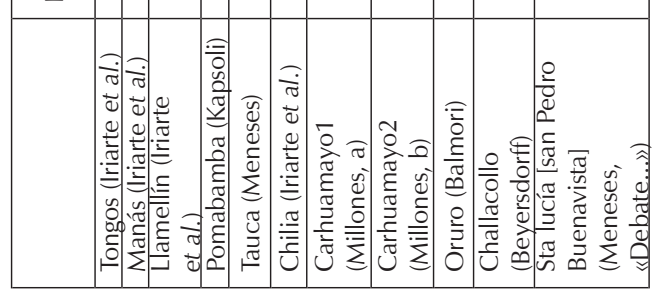




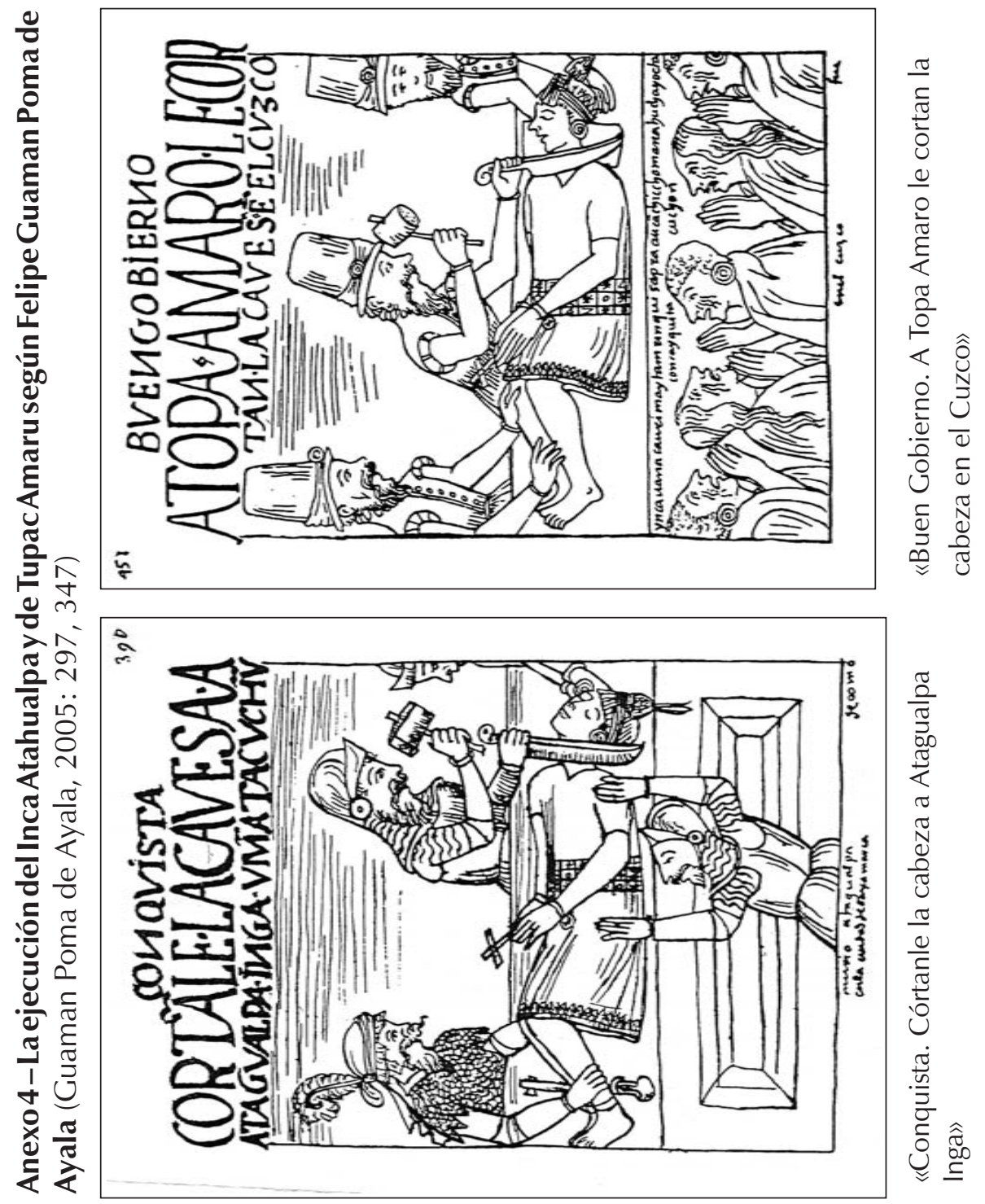


Anexo 5 - «La ciudad fuerte de Santa Cruz de Chile» (Guaman Poma de Ayala, 2005: 869)

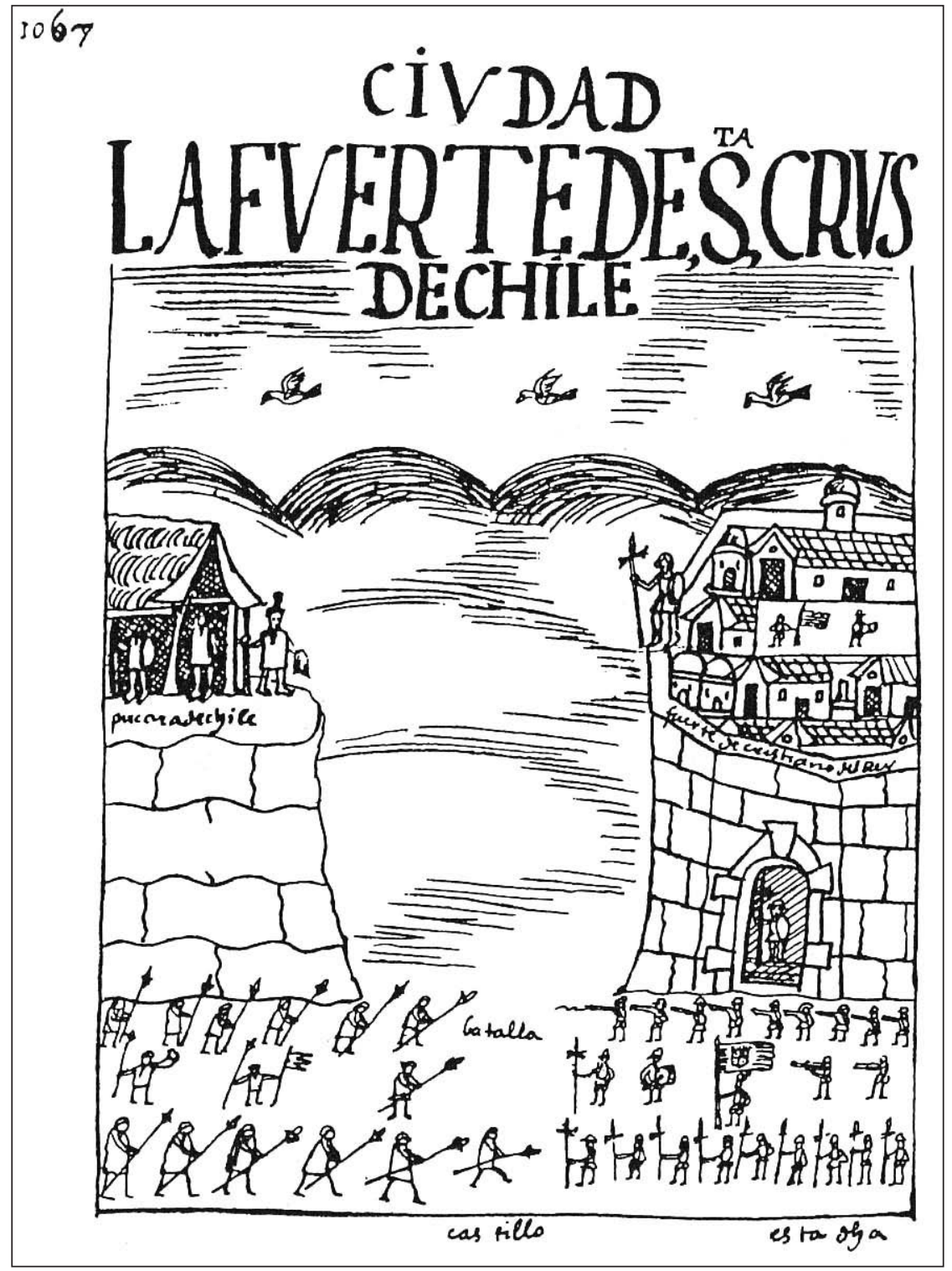


Anexo 6 - Batallas representadas en qeros: a. batalla entre incas y españoles (Flores Ochoa et al., 1998: XIV)

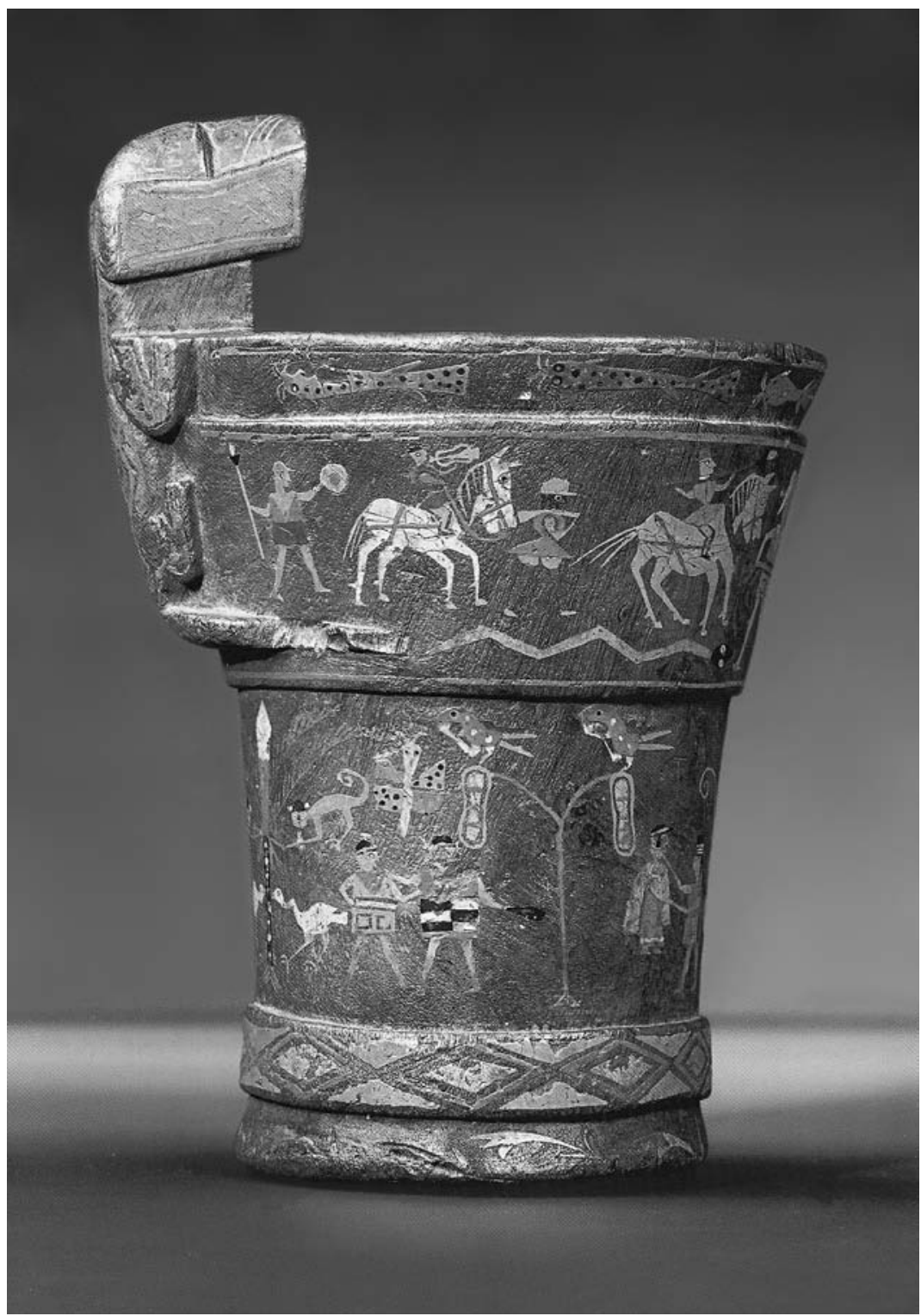


Las representaciones teatrales de «la muerte de Atahualpa»: ¿una herencia de «moros y cristianos»?

b. batallas entre incas y chunchos (LIEBSCHER,1986: 59-60)
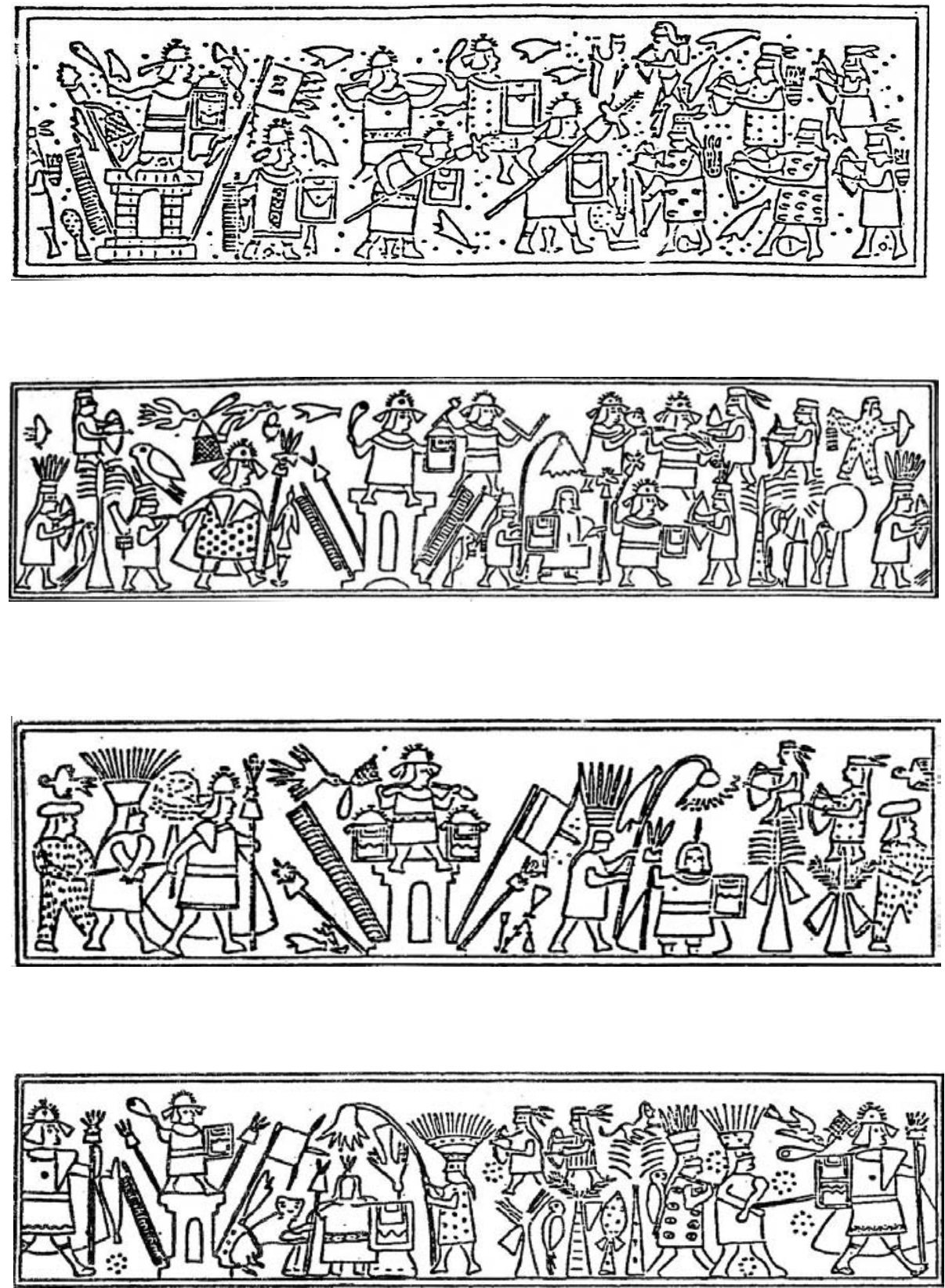
c. batalla entre incas y chancas (Flores Ochoa, 1998: 170)

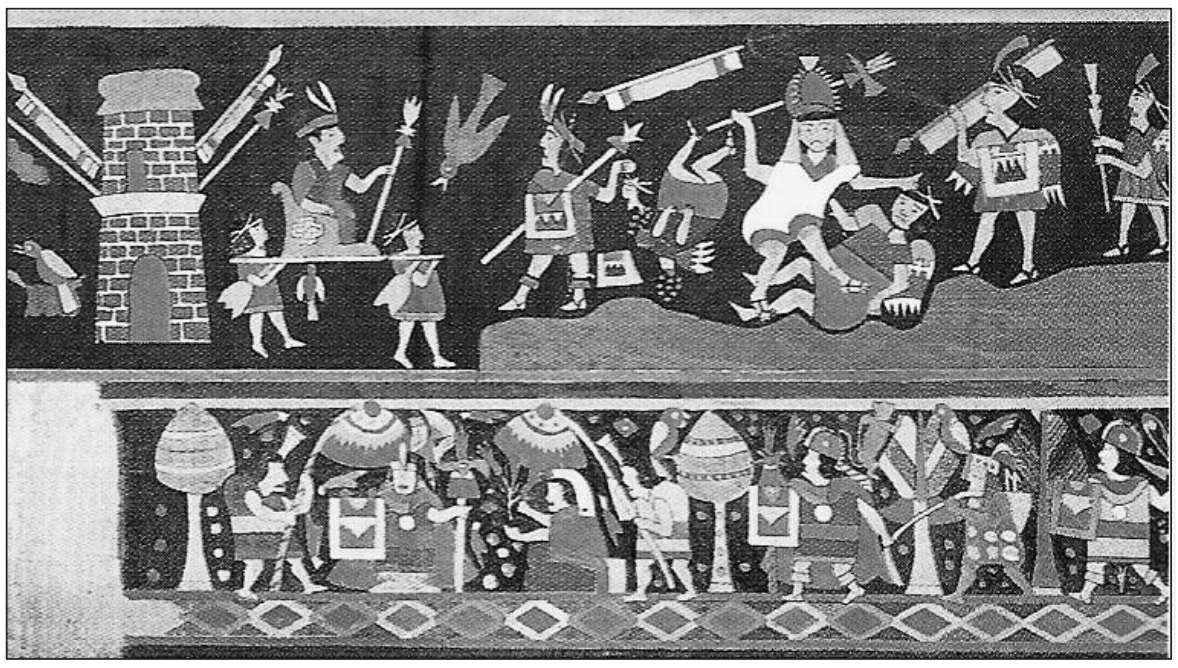

d. batalla entre incas y españoles con el auxilio de Santiago (Flores Ochoa, 1998: 265, 266)
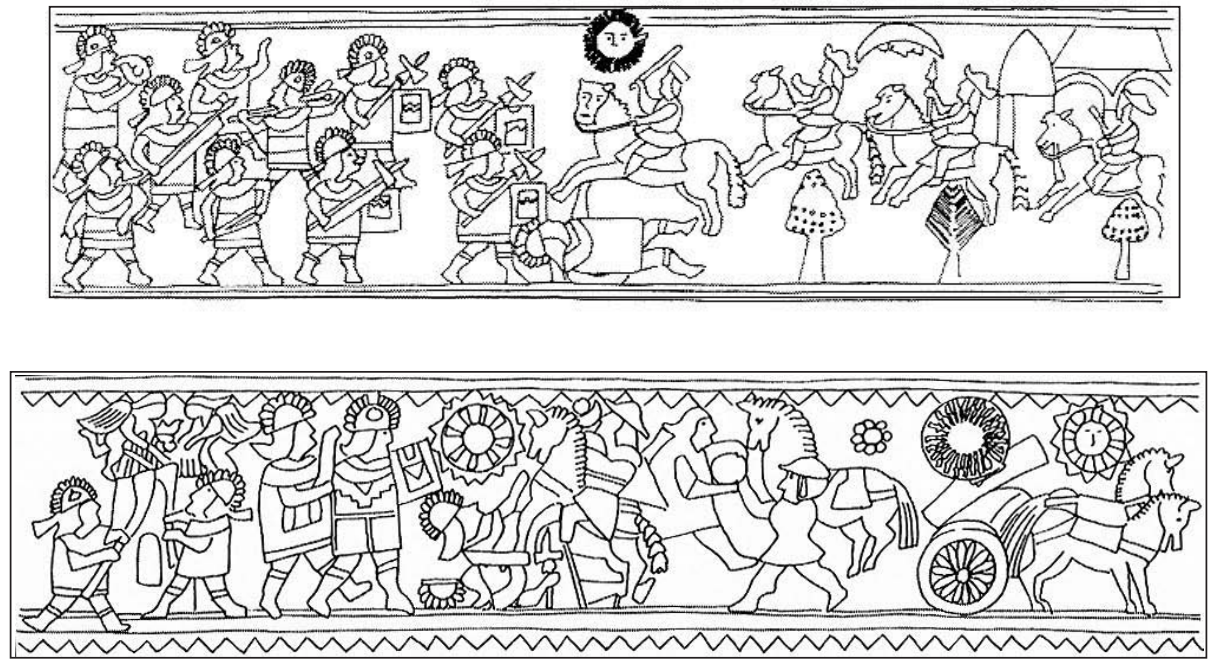
Las representaciones teatrales de «la muerte de Atahualpa»: ¿una herencia de «moros y cristianos»?

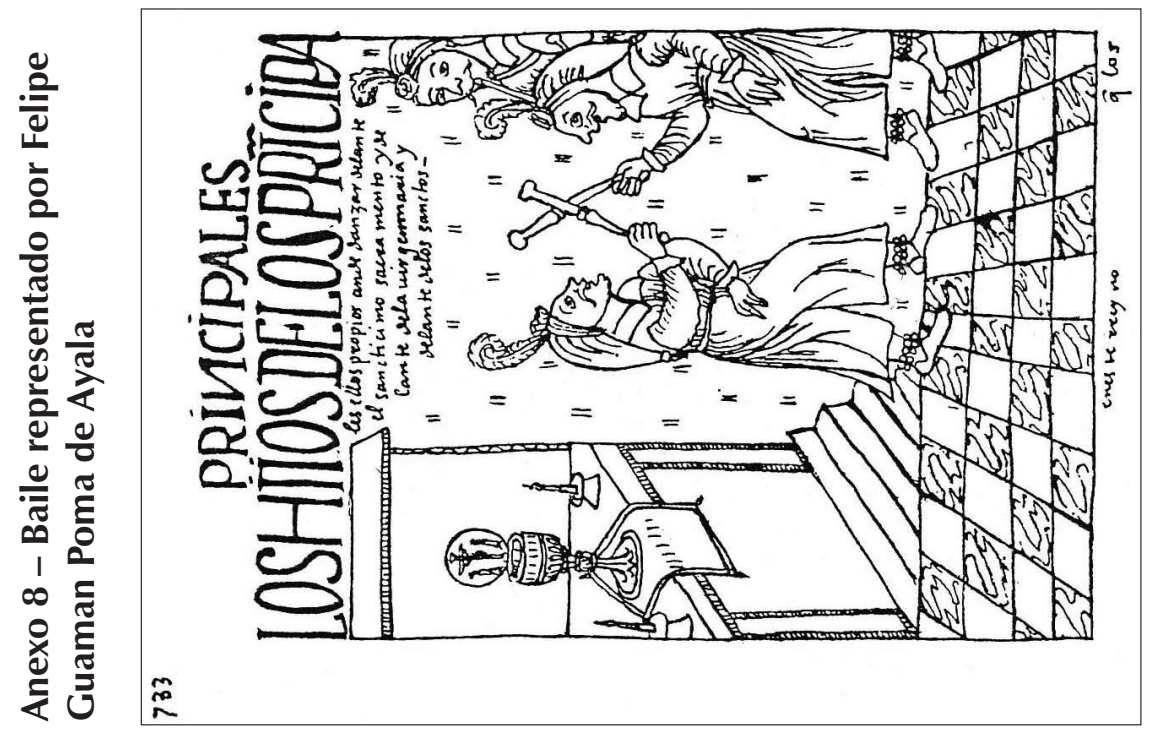

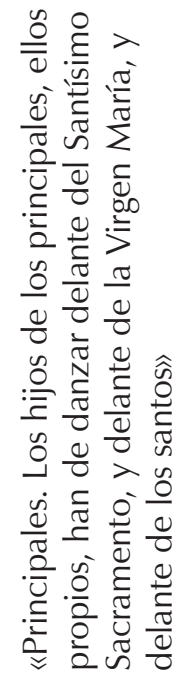

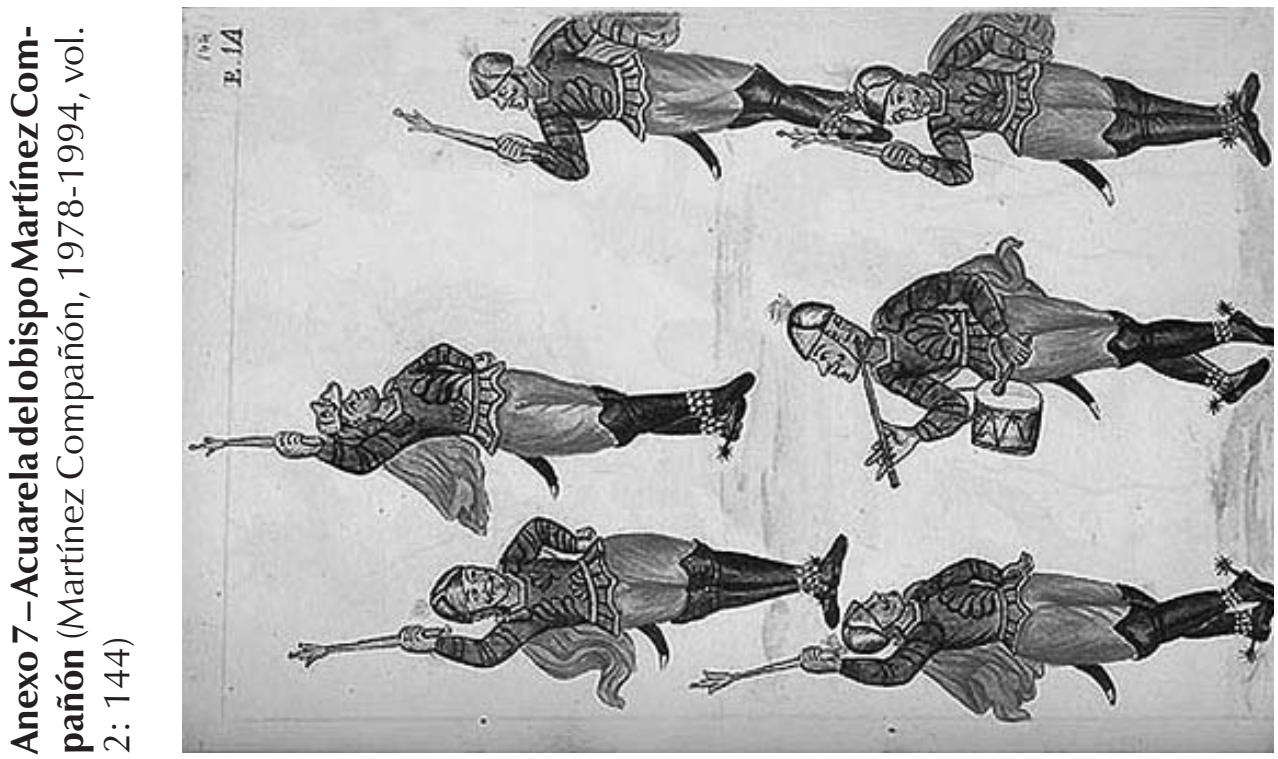

